\title{
Nonlinear Analysis and Post-Test Correlation for a Curved PRSEUS Panel
}

\author{
Kevin Gould ${ }^{1}$ \\ Analytical Mechanics Associates, Inc., Hampton, VA 23666 \\ Andrew E. Lovejoy ${ }^{2}$ and Dawn Jegley ${ }^{3}$ \\ NASA Langley Research Center, Hampton, VA 23681 \\ Albert L. Neal ${ }^{4}$ \\ The Boeing Company, Berkeley, MO 63134 \\ Kim A. Linton ${ }^{5}$ \\ The Boeing Company, Seal Beach, CA 90740 \\ and \\ Andrew C. Bergan ${ }^{6}$ and John G. Bakuckas Jr. ${ }^{7}$ \\ FAA William J. Hughes Technical Center, Atlantic City International Airport, NJ 08405
}

\begin{abstract}
The Pultruded Rod Stitched Efficient Unitized Structure (PRSEUS) concept, developed by The Boeing Company, has been extensively studied as part of the National Aeronautics and Space Administration's (NASA's) Environmentally Responsible Aviation (ERA) Program. The PRSEUS concept provides a light-weight alternative to aluminum or traditional composite design concepts and is applicable to traditional-shaped fuselage barrels and wings, as well as advanced configurations such as a hybrid wing body or truss braced wings. Therefore, NASA, the Federal Aviation Administration (FAA) and The Boeing Company partnered in an effort to assess the performance and damage arrestments capabilities of a PRSEUS concept panel using a full-scale curved panel in the FAA Full-Scale Aircraft Structural Test Evaluation and Research (FASTER) facility. Testing was conducted in the FASTER facility by subjecting the panel to axial tension loads applied to the ends of the panel, internal pressure, and combined axial tension and internal pressure loadings. Additionally, reactive hoop loads were applied to the skin and frames of the panel along its edges. The panel successfully supported the required design loads in the pristine condition and with a severed stiffener. The panel also demonstrated that the PRSEUS concept could arrest the progression of damage including crack arrestment and crack turning. This paper presents the nonlinear post-test analysis and correlation with test results for the curved PRSEUS panel. It is shown that nonlinear analysis can accurately calculate the behavior of a PRSEUS panel under tension, pressure and combined loading conditions.
\end{abstract}

${ }^{1}$ Structural Engineering Analyst, Structural Mechanics Group, MS 190.

${ }^{2}$ Senior Aerospace Engineer, Structural Mechanics \& Concepts Branch, MS 190, Senior Member AIAA.

${ }^{3}$ Senior Aerospace Engineer, Structural Mechanics \& Concepts Branch, MS 190, Associate Fellow AIAA.

${ }^{4}$ Structural Engineering Analyst, Boeing Research \& Technology.

${ }^{5}$ Senior Design Engineer, Advanced Structures, Boeing Research \& Technology.

${ }^{6}$ FAA-Drexel Fellowship Student, Drexel University Mechanical Engineering and Mechanics Dept, FAA Tech Center, Student Member AIAA.

${ }^{7}$ Senior Research Engineer, Structures and Materials Dept, FAA Tech Center. 


\section{Introduction}

$\mathrm{T}$ he Pultruded Rod Stitched Efficient Unitized Structure (PRSEUS) ${ }^{1}$ concept is a light-weight, low cost and high performance composite structure. In a combined effort by NASA, the Federal Aviation Administration (FAA) and The Boeing Company, a full-scale panel was designed, analyzed, fabricated and tested. The purpose of this joint effort was to assess the damage containment features of a full-scale curved PRSEUS panel using the FAA FullScale Aircraft Structural Test Evaluation and Research (FASTER) facility. Testing would demonstrate the damage arresting capabilities and the overall strength of the panel containing large area damage. In September 2011, testing was conducted in the FASTER facility by subjecting the curved PRSEUS panel to tensile, internal pressure and combined loading. The panel was tested in three different phases: pristine, with barely visible impact damage (BVID), and with large area damage. The panel design, pre-test analysis, modifications to the FASTER facility, test procedure and results have been previously published. ${ }^{2-5}$ The purpose of this paper is to document nonlinear posttest analysis and test correlation, focusing on the global response data obtained from the curved PRSEUS panel test. In this paper the PRSEUS concept and the curved panel is described, followed by a description of the testing scenario. Then, the nonlinear analysis is presented and the analytical and experimental results compared. The ability to accurately calculate the global behavior of a curved PRSEUS panel subjected to internal pressure and axial tension loadings is presented.

\section{The PRSEUS Concept}

PRSEUS is an integral structural concept ${ }^{6-9}$ that evolved out of stitching technology development from the NASA-Boeing Advanced Composites Technology program in the 1990s. ${ }^{10}$ In the PRSEUS concept, skins, frames, stringers and tear straps are all integrated together and stitched, then infused and cured in an out-of-autoclave process. ${ }^{1}$ An expanded view of a PRSEUS stiffener intersection is shown in Fig. 1. By assembling all of the stiffening elements together first and then stitching, the need for fasteners is almost eliminated. Continuous frame caps and stringer tear straps overlap each other at the stiffener intersections. The frames can be made full depth, eliminating the need for a separate shear tie since the frames are essentially continuous. Although the frame flanges and part of the web are cut, the frame flanges joggle over the stringer flanges and are stitched in place. The narrow slot in the frame is just large enough to allow the stringer web and pultruted rod to pass through. This feature eliminates the large mouse holes common in many existing designs. Stitching provides the out of plane strength to react pressure loads. Eliminating fasteners reduces the need for local pad-ups, saving weight and manufacturing time. It also eliminates the cost of the fasteners, and time to drill and install the fasteners. Integrating all of the members into one assembly insures that all of the parts fit together without the need for shimming and drastically reduces the piece part count. This approach reduces recurring costs and increases assembly rate. In addition, stitching suppresses delaminations, and produces a more damage tolerant design by arresting the progression of cracks. Another key to the PRSEUS concept is the pre-cured pultruded rod that is located at the top of the stringer which passes through the frames, providing an uninterrupted load path. This high modulus member raises the neutral axis of the stringer cross section, increasing the bending performance of the panel. These efficient structural stiffening members (frames and stringers) provide the majority of the panel stiffness, permitting the use of minimum skin thickness for many applications.

PRSEUS panels are fabricated from warp-knit fiber architecture stacks of dry AS4 carbon fiber, pultruded carbon fiber rods and Rohacell foam. The pre-kitted stacks have a stacking sequence of $\left[45 /-45 / 0_{2} / 90 / 0_{2} /-45 / 45\right]_{\mathrm{T}}$, which results in a cured stack thickness of approximately 0.052 inches. The pultruded rods are Toray unidirectional T800 fiber with a 3900-2B resin, and the frame stiffeners are filled with the Rohacell foam. The skin, frames, and stringers are stitched through-the-thickness into a dry preform using Vectran thread. The preform is then infused with HexFlow VRM 34 resin using Boeing's Controlled Atmospheric Pressure Resin Infusion (CAPRI) process. ${ }^{1}$ This process results in a large unitized stiffened panel with no fasteners that is ready for trim.

\section{Panel Description and Test Procedure}

An image of the curved PRSEUS test panel is shown in Fig. 2, with its test region outlined by the red dashed line. The panel has nominal dimensions of 127 inches long and 75 inches wide, with a 90-inch radius of curvature. The panel comprises seven full-length rod-stiffened stringers and five foam-core frames. The skin in the test section is 0.052 inches thick. The 0-degree orientation of the skin is parallel to the frames. Stringer spacing was 7.8 inches and frame spacing was 24 inches. Additionally, pad-ups are located around the edges of the panel to reduce the bearing stresses at the bolted interfaces and ease the load into the thin skin at the test section. Stringer and frame cross-sections are depicted in Fig. 3. Nominal stringer and frame heights, measured from the outer mold line 
(OML), are 1.44 and 3.95 inches, respectively. A detailed description of the panel design and fabrication is presented in Ref. 5.

Testing was performed in the FASTER test fixture that was modified to use two sets of seven axial loaders aligned to the neutral axis of each stringer at both ends of the panel for the axial tension loads. Seven hoop loaders were attached to the skin along both straight edges of the panel, and five frame loaders were connected directly to both ends of the frames to resist the internal pressure loads. Fig. 4 shows the panel installed in the FASTER test fixture. The axial loader support beams and axial loaders replaced the previous FASTER fixture axial loader mechanisms to increase the axial load capacity from 100 kips to 840 kips. This increase in axial load was necessary to statically test the PRSEUS panel to ultimate load and to ultimately fail the panel with large area damage. Additionally, the internal frame loaders were modified to be able to move freely in the axial direction to prevent large artificial side loads from developing on the frames as a result of the panel elongating under axial load. A more detailed description of the panel test set-up and testing can be found in Refs. 2-4.

The PRSEUS panel was instrumented with strain gages, linear variable displacement transducers (LVDTs), and an ARAMIS digital image correlation (DIC) system. The center of the panel OML was painted with a speckle pattern for the DIC system. The locations of the strain gages, LVDTs and the speckled region are shown in Fig. 5. Strain gages were used to measure the strains in regions of interest and to monitor load introduction into the test region of the panel. Displacement transducers measured the axial and radial deformations of the panel. The DIC system recorded full-field displacements and strains on the panel OML. More details of the panel instrumentation are given in Refs. 2-4. The nomenclature for identifying frames as F-1 through F-5 and stringers as S-1 through S-7 is shown in Fig. 5 and will be used throughout this paper to identify their locations on the panel.

During testing, the panel was subjected to axial load, pressure load, and combined axial and pressure loads in three phases, with the test series for each phase of testing shown in Table 1. Phase I loading was performed on the pristine panel for axial load up to $100 \%$ design limit load (DLL), pressure only load up to $133 \%$ of nominal operating pressure (P), and combined axial and pressure limit loads of 100\% DLL and $100 \%$ P. After Phase I testing was complete, barely visible impact damage (BVID) was imparted on the OML at the edge of the central stringer flange, centered between frames F-2 and F-3. Loading for Phase II duplicated Phase I limit loading and added ultimate load conditions of axial load to $150 \%$ DLL, pressure only load to $200 \% \mathrm{P}$, and combined loads of $150 \%$ DLL and $150 \%$ P. After Phase II loading was complete, large area damage was machined into the panel that encompassed the original BVID impact site. The large area damage was a notch that extended from mid-bay to mid-bay severing the central stringer as shown in Fig. 6. The notch was approximately 7.8 inches long and 0.3 inches wide with semi-circular tips. It was located approximately 51.5 inches from the end of the panel. Phase III loading included four load conditions, namely a pressure-only load condition up to $115 \% \mathrm{P}$, a combined load condition of 100\% DLL axial and 100\% P, an axial load condition of $100 \%$ DLL, and a combined load condition of $100 \% \mathrm{P}$ and axial loading to catastrophic failure. The typical profiles of the loads applied to the test specimen are shown in Fig. 7 for the combined 100\% P and 100\% DLL axial loads. Note that the loads during the test are applied using a sinusoidal function. Also, note the small oscillations in the pressure load, which are a function of the control system where pressure fluctuations of 0.2 psig peak-to-peak are possible. These pressure fluctuations can result in radial deflection fluctuations of 0.02 inches.

Table 1. Load sequences.

\begin{tabular}{|c|c|c|c|}
\hline \multirow{3}{*}{ Test Phase } & \multirow{2}{*}{ Load Condition } & \multicolumn{2}{|c|}{ Relative Applied Loads* } \\
\cline { 2 - 4 } & & Pressure (\% P) & Axial (\% DLL) \\
\hline \multirow{3}{*}{ I } & Internal Pressure & 133 & 100 \\
\cline { 2 - 4 } & Axial Tension & - & 100 \\
\cline { 2 - 4 } & Combined & 100 & - \\
\hline \multirow{4}{*}{ II } & Pressure & 133 & 100 \\
\cline { 2 - 4 } & Axial Tension & - & - \\
\cline { 2 - 4 } & Combined & 100 & 150 \\
\cline { 2 - 4 } & Pressure & 200 & - \\
\cline { 2 - 4 } & Axial Tension & - & 100 \\
\cline { 2 - 4 } & Combined & 150 & 100 \\
\hline \multirow{4}{*}{ III } & Internal Pressure & 115 & 184 \\
\cline { 2 - 4 } & Combined & 100 & - \\
\cline { 2 - 4 } & Axial Tension & 100 & \\
\cline { 2 - 4 } & Combined & & \\
\hline
\end{tabular}

$* 1 \mathrm{P}=9.2 \mathrm{psi} ;$ Axial DLL = $227.3 \mathrm{kips}$ 


\section{Finite Element Nonlinear Analysis Approach}

The objective of the analysis effort was to calculate accurately the global panel response, and to compare the analysis results to the test data. Detailed damage calculations and damage growth predictions are beyond the scope of this paper. Pretest predictions were based on a geometrically linear finite element analysis and were developed for phases I, II and III. These predictions are presented in reference 3. The geometrically nonlinear finite element analysis described herein used the same finite element model as the linear analysis, but substantial changes were made to more accurately capture load introduction and panel behavior for the pristine panel. The model was then modified further to examine the global behavior of the panel with large area damage.

A geometrically nonlinear analysis was performed using MSC/NASTRAN. ${ }^{11}$ A wireframe depiction of the model is shown in Fig. 8. All of the composite structure was modeled using shell elements except for the stringer rods which were modeled using beam elements. Typical shell elements within the model are approximately 0.5 inches on a side. In order to obtain the correct load introduction and boundary conditions, portions of the FASTER fixture were included in the finite element model. Frame, hoop, and axial load fixtures were modeled explicitly using beam elements. The frame loaders were allowed to rotate in-plane and translate in the panel's axial direction. The hoop loaders could only rotate about a restrained pivot point located about one foot below the top of each hoop loader arm. The axial loaders at the ends of the panel were restrained from motion in all directions except the axial direction. Desired loads were imposed on the panel by applying prescribed forces to the FASTER load introduction components as illustrated in Fig. 8(a) by dashed arrows. Internal pressure loading, however, was applied directly to the panel's interior surface of the skin and skin/flange elements. All preprocessing and post-processing of the finite element model was performed using MSC/Patran. ${ }^{12}$ All calculations were performed using NASTRAN's SOL 106 nonlinear static analysis procedure. The model contains approximately 159,000 nodes and 162,000 elements. Properties for the model were obtained from Ref. 1 and are shown in Table 2.

Table 2. Nominal material properties.

\begin{tabular}{|c|c|c|c|c|}
\hline Property & $\begin{array}{c}\text { Stack } \\
\text { Compression* }\end{array}$ & $\begin{array}{c}\text { Stack } \\
\text { Tension* }\end{array}$ & Foam & Rod \\
\hline $\begin{array}{c}\text { Longitudinal stiffness, } \\
\text { Msi }\end{array}$ & 9.23 & 10.25 & 0.0261 & 18.0 \\
\hline Transverse stiffness, Msi & 4.66 & 5.07 & 0.0261 & 1.0 \\
\hline Shear stiffness, Msi & 2.26 & 2.48 & 0.0102 & 6.0 \\
\hline Poisson's ratio & 0.397 & 0.403 & 0.29 & 0.2 \\
\hline
\end{tabular}

* 0.052 inches thick, [44/44/12] percent 0/45/90

This paper focuses on the global response of the panel during Phases I and III, since Phase II limit load testing resulted in negligible global response changes when compared to Phase I. Phase I loading conditions were simulated using the pristine panel analysis model shown in Fig. 8(a) to obtain displacement and strain results for comparison to the panel test data. Phase III loading conditions on the panel with the two-bay notch were simulated using the model shown in Fig. 8(b), which incorporates the 7.8 inch notch severing both skin and stringer. As evident in Fig. 9(a), the skin regions where gages were located possess a higher mesh density than those regions of the panel which did not have instrumentation installed. The mesh in the vicinity of the notch is shown in Fig. 9(b).

The loads imposed in the analyses were applied using a linear ramp, in contrast to the sinusoidal load function that was applied during the test. This loading approach was done both to simplify the analysis, and because the test load was applied at a much slower rate at the beginning and end of the ramp so that the majority of the load was applied fairly linearly. Additionally, since the loads in the test were applied slow enough not to impart any transient response, a quasi-static load condition, the form of the load ramp during analysis is not important, rather, only the load level during comparison is important. 


\section{Results and Discussion}

In this section, a comparison between the nonlinear analysis results and the test data is presented for Phase I and III load conditions. The Phase I results for the pristine panel are presented first, followed by the Phase III results for the panel with large area damage. To aid in interpretation of presented data, a small image of the panel is inset into each plot to identify the locations of the instrumentation for which data is being plotted. Identification is achieved by superimposing colored markers at the locations of the instrumentation, providing easy reference to Fig. 5 where the instrumentation locations are provided in more detail. Test data is presented in the plots using solid lines, and the analysis data is presented in the plots using dashed lines. Also, the labels corresponding to the analysis calculations have an asterisk appended to them.

\section{A. Phase I Correlation}

Nonlinear analysis of the pristine curved PRSEUS panel was performed using the Phase I loads, and the results compared to the test data. First, analysis results were compared to the LVDT data for the three load conditions. The comparison of the results for the third load condition, 100\% P and 100\% DLL axial load, is shown in Fig. 10. Radial displacements are compared in Fig. 10(a) and axial displacements are compared in Fig. 10(b). The trends between the analysis and test for this load condition are very similar, and show reasonable agreement. The differences seen between the analysis and test may be due to the analysis' inability to capture rigid body motions of the panel or slop that is present within the complex load fixtures. This shortcoming of the model manifested itself when comparing the first two load conditions, where calculated radial displacements could be on the order of the the slop within the system. For this reason, the LVDT comparisons for the first two load conditions are not presented herein. Additionally, note the oscillations in the radial displacements shown in Fig. 10(a), a phenomenon that is also seen in the applied pressure load shown in Fig. 7. The oscillations are developed by the control system for the pressure load, and are also much more apparent when the measured quantity is very small. However, the main goal is to compare the strain within the panel, or the actual response of the panel structure, which is likely unaffected by the small errors seen between analysis and test for the LVDTs. Therefore, strain data is compared to examine how accurately the nonlinear analysis calculates the measured panel response.

Strain calculations for the Phase I load conditions are presented in Figs. 11, 12 and 13. Axial strains across the width of the panel are shown in part (a) of the figures at three locations between frames 3 and 4 . Hoop strains along the length of the panel are shown in part (b) of the figures at the intersection of the center stringer (S-4) and frames F-2, F-3 and F-4. The 100\% P load conditions strains are shown in Fig. 11, where it is seen that the test data exhibits a mildly nonlinear response. Axial strain calculations correlate fairly well with the test data for all load conditions and key global response locations plotted (see Figs. 11, 12 and 13). The calculations match the data well at both low $(450 \mu \varepsilon)$ and higher $(3500 \mu \varepsilon)$ axial strain magnitudes. Calculated hoop strains do not correlate as consistently as the calculated axial strains, but the calculated hoop strains are adequate for gauging Phase I global panel response. For example, Fig. 13(b) accurately reflects the reversal of the hoop strain response of the panel for the combined loading condition, a good indicator of the fidelity of the FEM.

\section{B. Phase III Correlation}

Similarly, Phase III loading was applied to the PRSEUS panel model containing large area damage and results compared to the data. Fig. 14 presents the calculated Phase III LVDT data correlation for the combined pressure (100\% P) and axial load (100\% DLL) condition. The Fig. 14(a) calculated radial displacement response characterizes the test data well. The discrepancy between the calculated and recorded radial LVDT displacement responses may be due in part to slight offset of the panel from its original position at the beginning of the test. The Fig. 14(b) axial displacement correlation shows good agreement with the recorded axial data. The calculated radial displacement response from the axial load portion of the loading is linear but deformation near the large area damage becomes nonlinear at approximately the 100\% P and 60\% DLL loading condition. This nonlinear radial response is best explained by a series of calculated radial deformation plots of the notched region. Table 3 captures deformation plots of the notched region for combined load conditions of $100 \% \mathrm{P}$ and axial load of $60 \%, 80 \%$ and $100 \%$ DLL respectively. The notched region of the model starts to buckle inward as the axial load approaches $70 \%$ DLL and continues moving inward with increased axial load. The center stringer is calculated to slightly roll as a result. 
Table 3 - Calculated Deformation of Notched Region

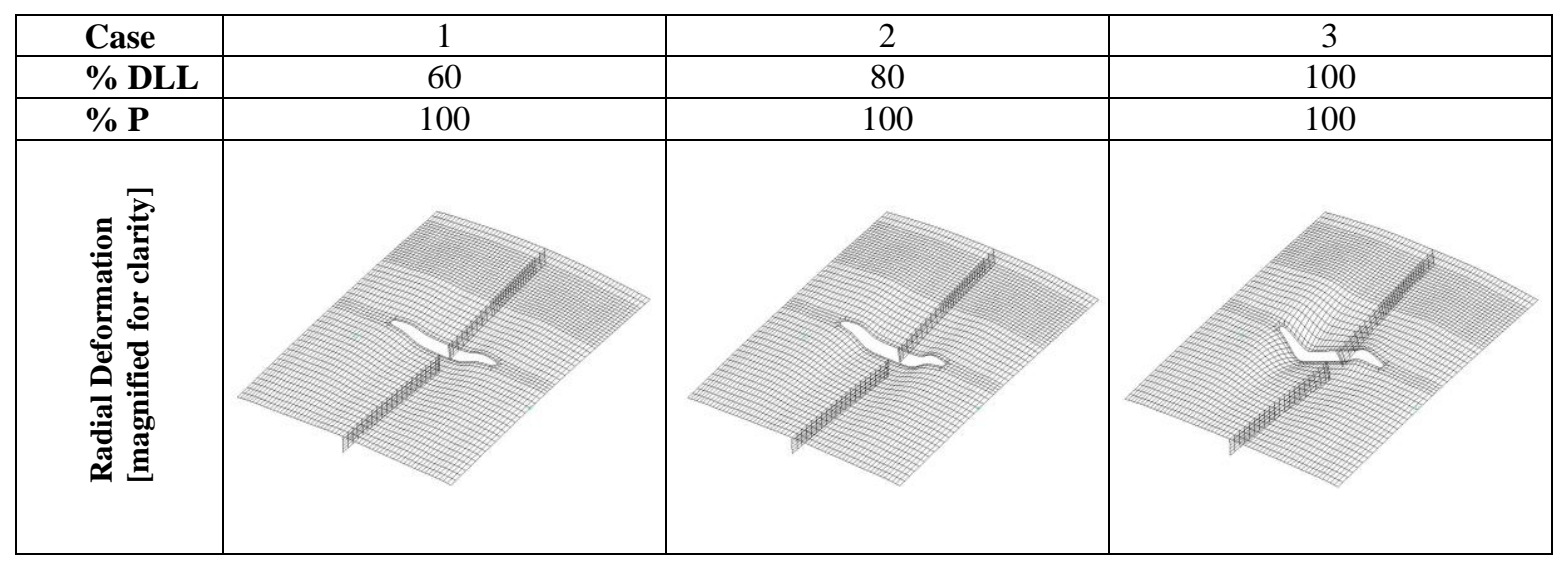

Fig. 15 presents strain response correlations for the notched damage region and gages along the notch's axis in particular. Fig. 15(a) calculations show excellent agreement with the experimental strain data recorded near the notch tips (on the IML side) by four strain gages (BS-45, BS-46, BS-48, and BS-49) oriented at 45 degrees. Further, Fig. 15(b) shows excellent agreement between the calculated and experimental strain data for strain gages AS-06, AS-09, and AS-10 located along the axis of the notch. Strain gage AS-07 (intended to mirror AS-09) malfunctioned during the test and therefore was excluded from the Fig. 15(b) plot. Strain gage AS-08, displaced by the machining of the notch, was deleted for Phase III data collection.

Fig. 16 captures the axial strain correlation for $0^{\circ}$ oriented skin gages which are located closest to the notch itself: specifically BS-37, BS-38, BS-39 and BS-40. Fig. 16 shows excellent correlation of calculated axial strain with test data up to approximately 190 kips, at which point the test data response becomes nonlinear as seen in the response recorded by gages BS-38 and BS-39 which straddle the center stringer, S-4.

Increased confidence in the analytical calculations was established from correlating calculations against the DIC data as well. Figs. 17, 18 and 19 compare analysis calculations with DIC contour plots, which enveloped the notched damage region at the $100 \%$ P plus $68 \%$ DLL load condition. This particular load condition is of interest because this is the load level at which the response was observed to become nonlinear at certain locations. An objective of this study was to document the applicability of a nonlinear analysis for calculating nonlinear response up to and including damage initiation. The contour images from analysis and DIC have identical contour scales, and thus contour distributions can be easily compared. In general, when using an analysis contour plot to assess local structural response, it is common practice to probe the values developed at nodes or elements which are near, but not at, discontinuities in the model. Therefore, using the Fig. 17(a) fringe plot as a basis for judging the axial strain near the notch tips, values corresponding to the orange contour region of the fringe color spectrum would be considered reasonable. Hence, strain near the notch tips is calculated to fall between 5000 and 6000 microstrain for the noted load condition. In the DIC plot, Fig. 17(b) shows the axial strain associated with the orange region of the contour color spectrum near the notch tips falls between 5500 and 6000 microstrain, which is fairly close in comparison to the analysis results. The Fig. 18 plots, which capture hoop strain within the speckled region, do not resemble closely in comparison, but the same general strain distribution is evident. In Fig. 18(a), the calculated range of strain values developed near the notch tips fall between 1500 and 2000 microstrain. Fig. 18(b), which shows the recorded hoop strain value of 1600 microstrain developed near the notch tips, matches calculations. The Fig. 19(a) calculated minimum and maximum axial displacement magnitudes show excellent agreement with the Fig. 19(b) DIC contour plot.

This study also yielded favorable correlation with experimental data for the strains developed in the stringers and frames in close proximity to the notch. Fig. 20(a) shows the calculated axial strains developed in the stringers agree very well with the experimental data captured by strain gages SF-42, SF-44, SF-50 and SF-52. And Fig. 20(b) depicts very good agreement between calculated strain developed in the frames and test data recorded by strain gages FF-35, FF-36, FF-54 and FF-55. Calculated axial strain response for gages FF-54 and FF-55 located on the center frame, F-3, becomes nonlinear after approximately 150 kips of axial load.

\section{Phase III Damage Initiation}

Capturing the damage propagation events observed during testing is beyond the scope of this analysis effort. However, an important consideration of this analysis effort was to assess if the damage initiation load obtained from 
test could be calculated without a more elaborate analysis such as a progressive failure analysis. In this section, analysis calculations are correlated with experimental events captured by strain gage and DIC data. Correlations are shown for analysis cases that correspond to the key damage events.

\section{Damage Initiation}

The calculated axial strain in the speckled region for the $100 \% \mathrm{P}+50 \%$ DLL $(\approx 142 \mathrm{kips})$ axial load level is shown in Fig. 21(a). The measured DIC axial strain contour for the 100\% P + 55\% DLL ( $\approx 153 \mathrm{kips})$ load level is shown in Fig. 21(b). Based on the Fig. 21(a) fringe contour and the earlier stated assumption about using contours to judge local structural response, the axial strains developed close to the notch tips are calculated to fall in the range of 5000 to 6000 microstrain. These calculated strain values correspond well to those captured in the DIC results in Fig. 21(b) near the notch tips. Visual damage was initially observed on the inner mold line at the notch tips for the $100 \% \mathrm{P}+58 \%$ DLL ( $\approx 160 \mathrm{kips})$ load condition. ${ }^{3}$

Since a progressive failure analysis was beyond the scope of this study, the current nonlinear analysis was combined with available data to achieve a correlation with the damage initiation load observed in the test. Design allowable and failure strain associated with the various regions of a stiffened PRSEUS panel are presented in Ref. 14. For the skin region subjected to a tensile load, the tension after impact (TAI) design allowable and the unnotched failure strain values are 5,900 and 10,000 microstrain, respectively. Assuming that the nonlinear analysis approximates the load at which damage near the notch tips initiates by using the TAI value, then the calculated axial damage initiation load would be the load at which strain near the notch tips approaches approximately 6,000 microstrain. Applying this simplified approach, the damage initiation load obtained from the nonlinear analysis is approximately $100 \% \mathrm{P}+60 \%$ DLL ( $\approx 153 \mathrm{kips})$. The calculated value of $153 \mathrm{kips}$ is near the observed experimental damage initiation load of approximately 160 kips. $^{3}$ Therefore, based on this good agreement between test and analysis, confidence in the existing analytical capabilities to correlate with the initial damage response of the PRSEUS panel is gained.

\section{Nonlinear Behavior}

Recall the calculations shown in Fig. 15(a) which relates to the $45^{\circ}$ oriented gages near the notch tips. The Fig. 15(a) plotted test data captures the nonlinear strain response initiated around 100\% P + 56\% DLL ( $\approx 143 \mathrm{kips})$ and $100 \%$ P $+61 \%$ DLL ( $\approx 156$ kips) load conditions respectively. A clear limitation of a static nonlinear analysis is that it cannot capture delamination and other damage which occurred at these load levels. ${ }^{3}$ Nevertheless, nonlinear analysis calculations can be beneficial in establishing load windows in which damage may be initiated. For example, the Fig. 15(a) analysis overlay does not pick up the initial strain response slope changes shown in the data, but there is a slope change in the analysis overlay at a higher load of approximately $100 \%$ P $+128 \%$ DLL $(\approx 290$ kips). Therefore, one could make calculated judgments about the potential of a damage event based on the fact that calculated strains near the notch tips in this particular case have reached or exceeded the design allowable level (as shown in Fig. 21(a)) coupled with a sudden slope change in the calculated strain response near the notched damage region. The calculated strain slope change at the locations near the notch tips occurs approximately at an additional 148 kips from the load at which the gages failed. ${ }^{3}$

\section{Concluding Remarks}

In summary, the purpose of this study was to demonstrate the effectiveness of a geometrically nonlinear analysis in generating sufficiently accurate global response calculations for a curved PRSEUS panel by correlation with test data. Results are presented in this paper for the pristine and damaged panels and test conditions including internal pressure, axial tension, and combined internal pressure and axial tension loadings.

In general, the global displacement calculations correlate well for all load conditions at higher response magnitudes, but are less accurate at lower response magnitudes. Displacement calculations correlate well with both point measurements and full-field data, which increased confidence in the analysis modeling and the nonlinear analysis procedure. The global strain calculations also correlate well with the experimental data for all load conditions. 


\section{References}

${ }^{1}$ Velicki, A., "Damage Arresting Composites for Shaped Vehicles, Phase I Final Report," NASA CR-2009-215932, September 2009.

${ }^{2}$ Bergan, A. C., Bakuckas, J. G., Lovejoy, A. E., Jegley, D. C., Awerbuch, J. and Tan, T. M. 2011. "Assessment of Damage Containment Features of a Full-Scale PRSEUS Fuselage Panel through Test and Teardown," to be presented, American Society for Composites Conference, October 2012, Dallas, TX.

${ }^{3}$ Bergan, A. C., Bakuckas, J. G., Lovejoy, A. E., Jegley, D. C., Linton, K. A., Neal, A., Korkosz, G. J., Awerbuch, J. and Tan, T. M. 2011. "Full-Scale Test and Analysis Results of a PRSEUS Fuselage Panel to Assess Damage-Containment Features," presented at the 2011 Airworthiness and Sustainment Conference, April 2-5, 2012.

${ }^{4}$ Bergan, A., Bakuckas, J., Lovejoy, A., Jegley, D., Linton, K., Korkosz, G., Awerbuch, J., and Tan, T.M., "Full-Scale Test and Analysis of a PRSEUS Fuselage Panel to Assess Damage-Containment Features," 2011 Airworthiness and Sustainment Conference, San Diego, CA, April 18-21, 2011.

${ }^{5}$ Linton, K., Neal, A., Mills, G., Velicki, A., and Thrash, P., "Design, Analysis, and Fabrication of a Curved PRSEUS Panel," Final report for NASA contract: NNL04AA11B/task order: NNL10AA99T, December, 2010.

${ }^{6}$ Velicki, Alex, and Hansen, Dan, "Novel Blended Wing Body Structural Concepts," NRA-03-LaRC-02 Maturation for Advanced Aerodynamic and Structures Technologies for Subsonic Transport Aircraft: Phase I Final Report, July $13,2004$.

${ }^{7}$ Air Vehicle Technology Integration Program (AVTIP), Delivery Order 0059: Multi-role Bomber Structural Analysis, AFRL-VA-WP-TR-2006-3067, K. Hoffman, MAY 2006, Final Report for 14 December 2004 - 08 May 2006, AFRL-VA-WPTR-2006-3067.

${ }^{8}$ Velicki,.A. and Thrash, P. J., "Advanced Structural Concept Development Using Stitched Composites," 49th AIAA/ASME/ASCE/SHS/ASC Structures, Structural Dynamics, and Materials Conference, 7-10 April 2008, Schaumburg, IL, AIAA Paper 2008-2329

${ }^{9}$ Jegley, D., "Influence of Impact Damage on Carbon-Epoxy Stiffener Crippling," American Society for Composites meeting, Sept 2010, Dayton, OH.

${ }^{10}$ Karal, M., "AST Composite Wing Study - Executive Summary," NASA/CR-2001-210650, Prepared for NASA, Langley Research Center under Contract NAS1-20546, March 2001

${ }^{11}$ MSC.NASTRAN 2004 Reference Manual, MSC Software Corporation, Santa Ana, CA, 2003.

${ }^{12}$ MSC.PATRAN Reference Manual, MSC Software Corporation, Santa Ana, CA, 2003.

${ }^{13}$ Albert, N. L., "PRSEUS Design Concept, 7-Stringer Minimum Gage Combined Loading (Pressure and Tension) Fuselage Panel with Barely Visible Impact Damage (BVID) and 2-Bay Notched Damage", ZA153422, Rev. B, Dec. 7, 2010.

${ }^{14}$ Yovanof, N., Structures Technology 2010 NBF Block Release Report, Damage Arresting Composites Project EOT-12014745-13608, 30 July 2009. 


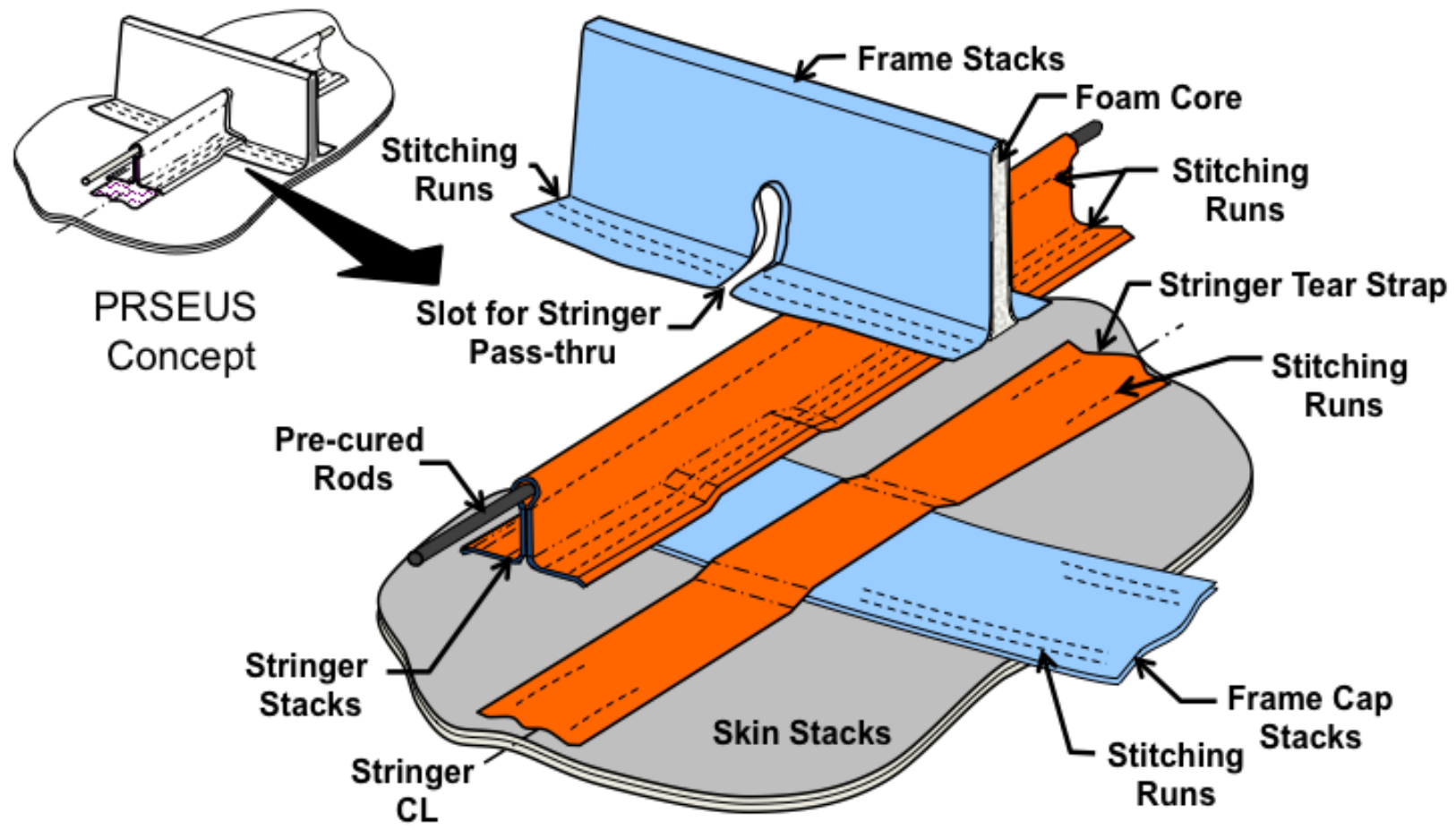

Figure 1. PRSEUS stiffener intersection expanded view. 


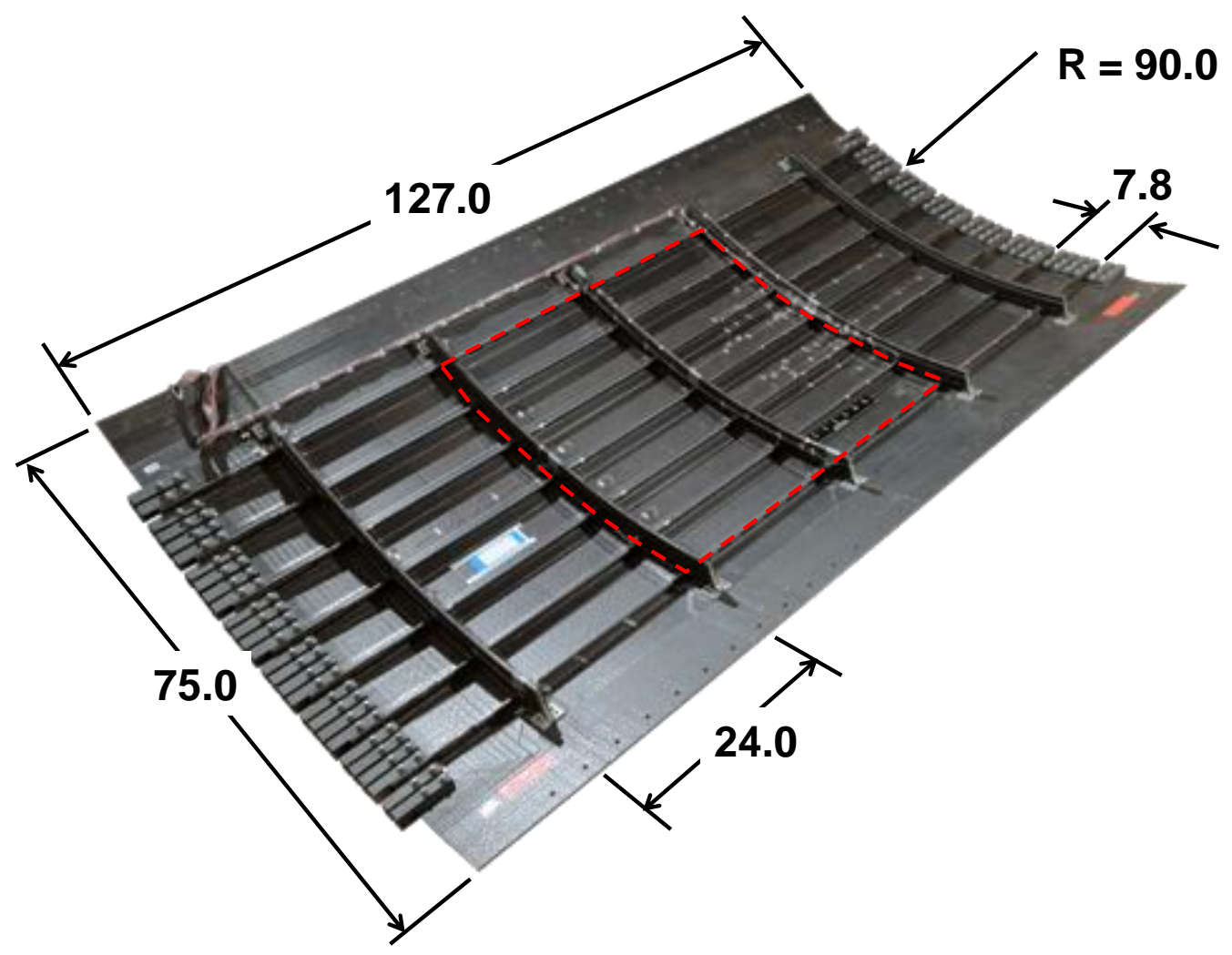

Figure 2. Curved PRSEUS test panel configuration (dimensions are in inches).

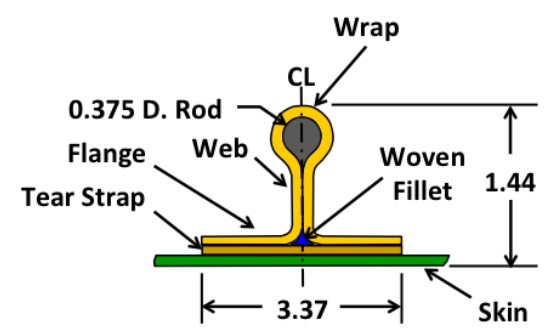

a) Stringer

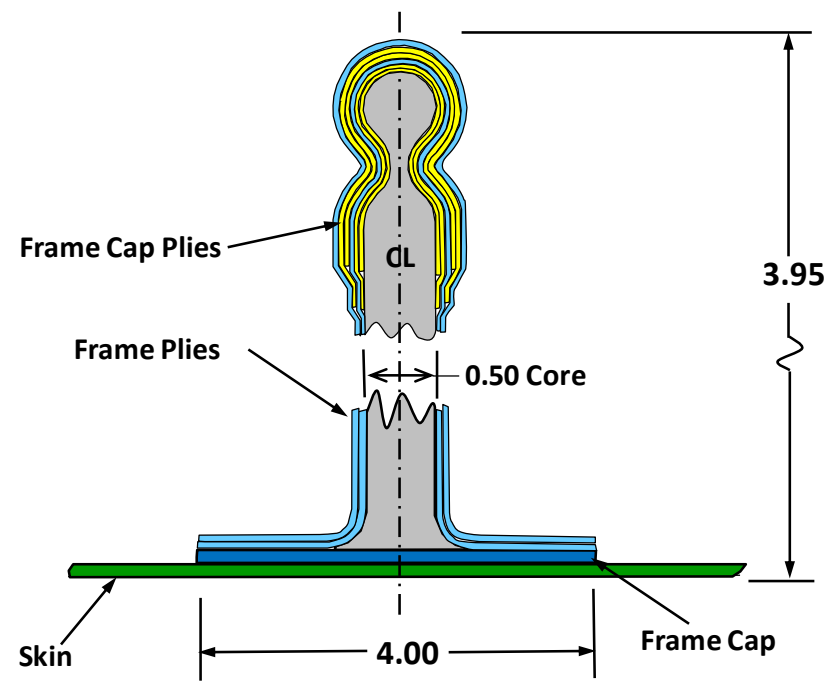

b) Frame

Figure 3. PRSEUS panel stringer and frame cross-sections. Dimensions are in inches. 


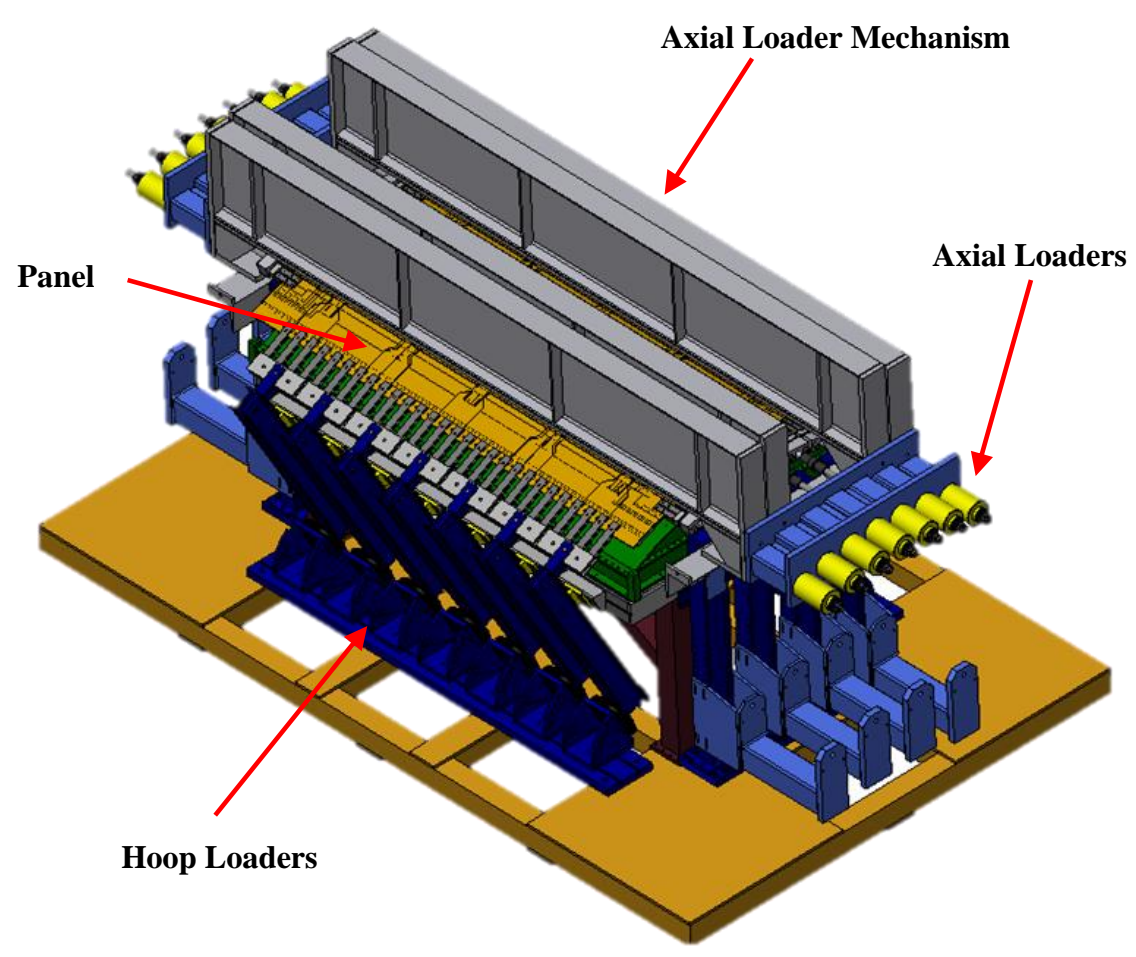

a) FASTER fixture

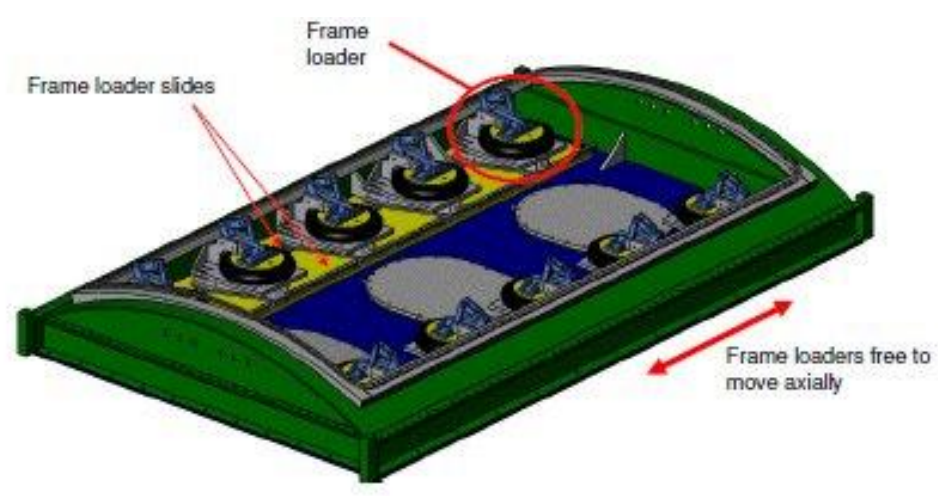

b) Frame loader slide system

Figure 4. FAA FASTER fixture configuration. 


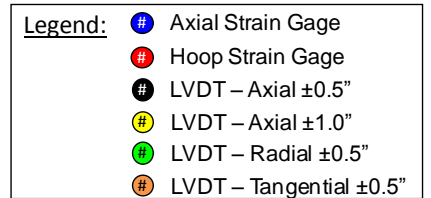

\section{Exterior Map}

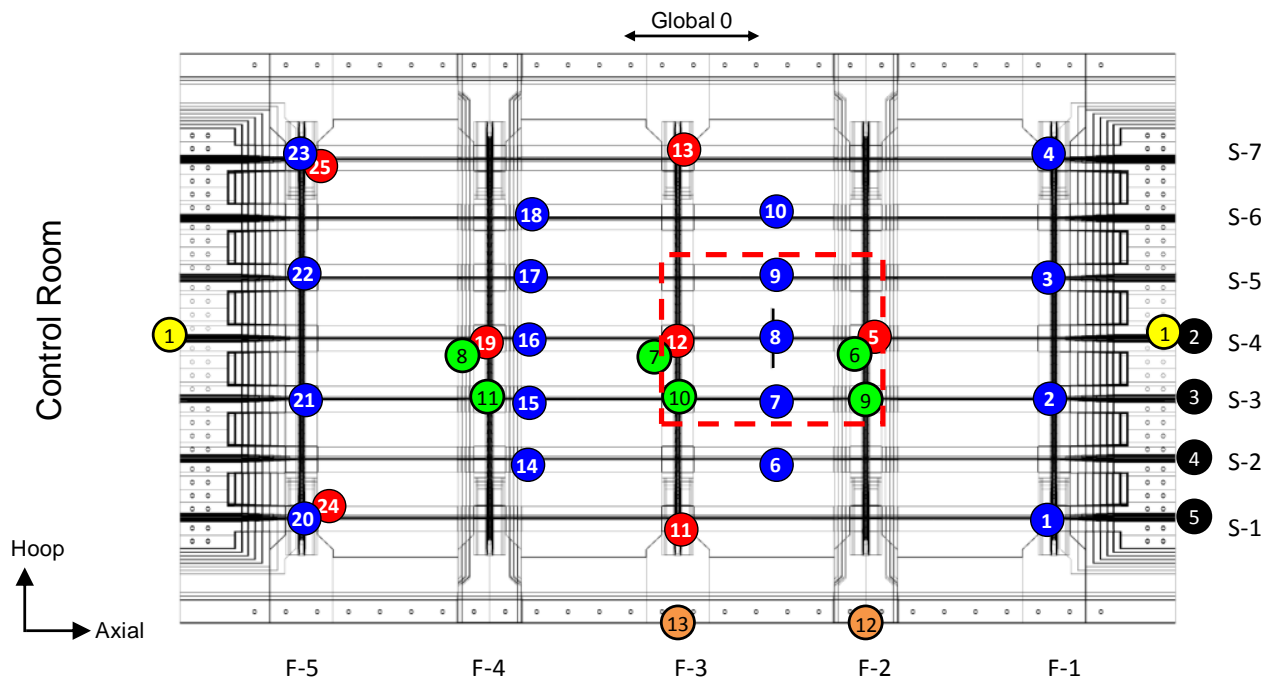

a) Outer mold line (OML)

\section{Interior Map}

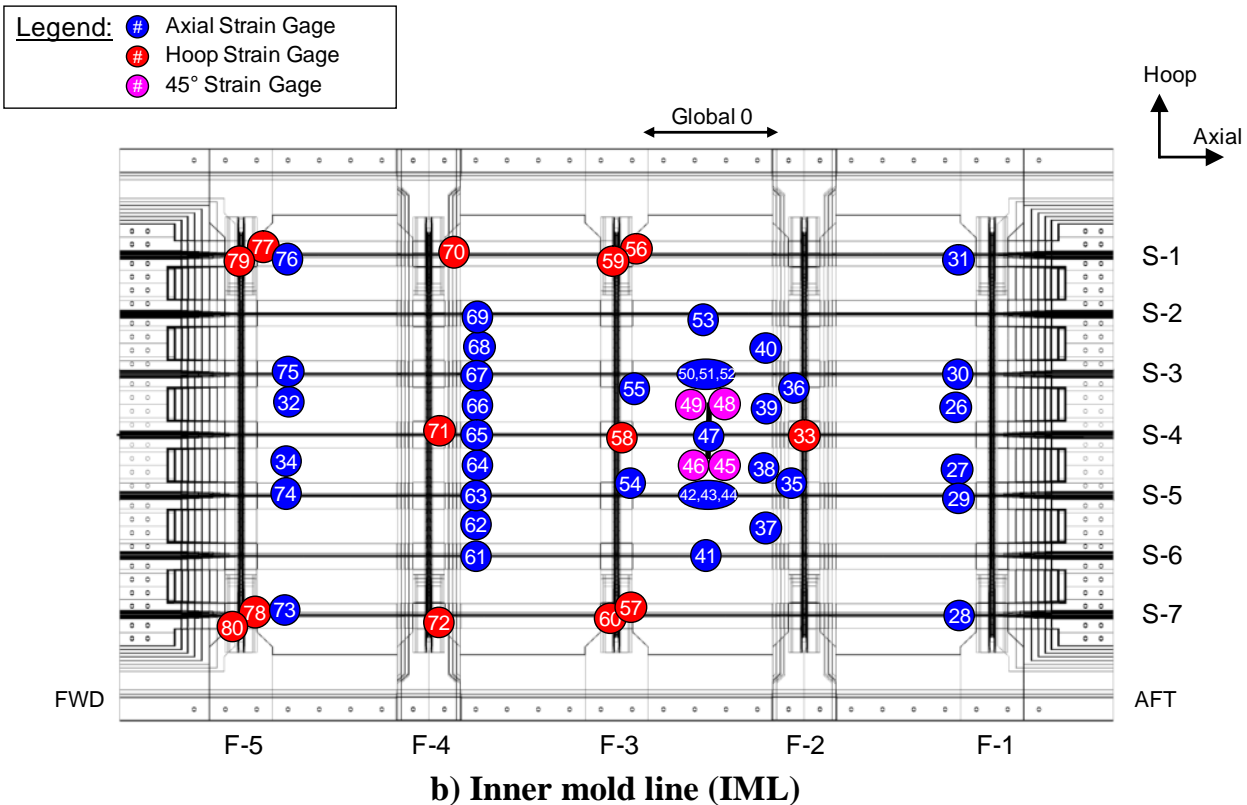

Figure 5. Location of LVDT's and strain gages. 


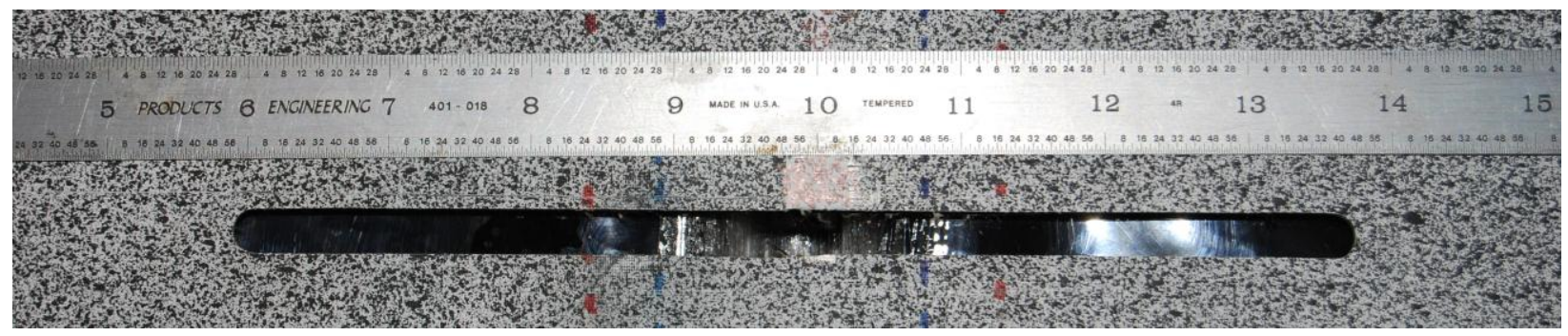

a) Outer surface

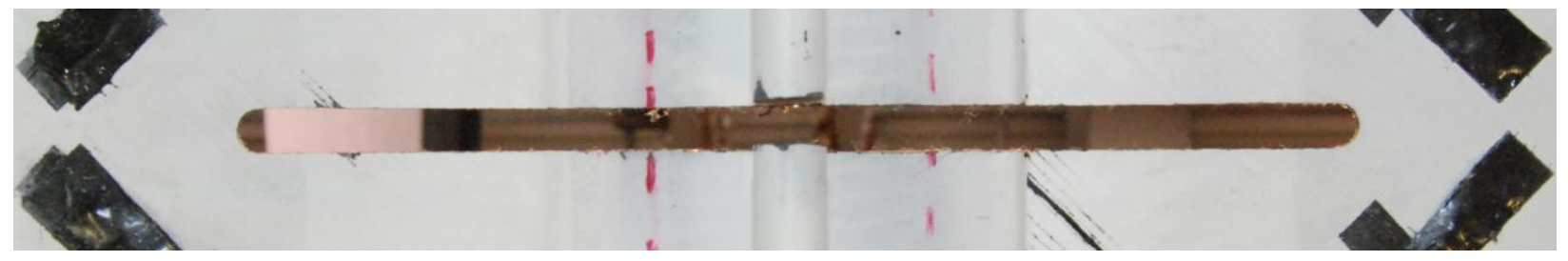

b) Inner surface

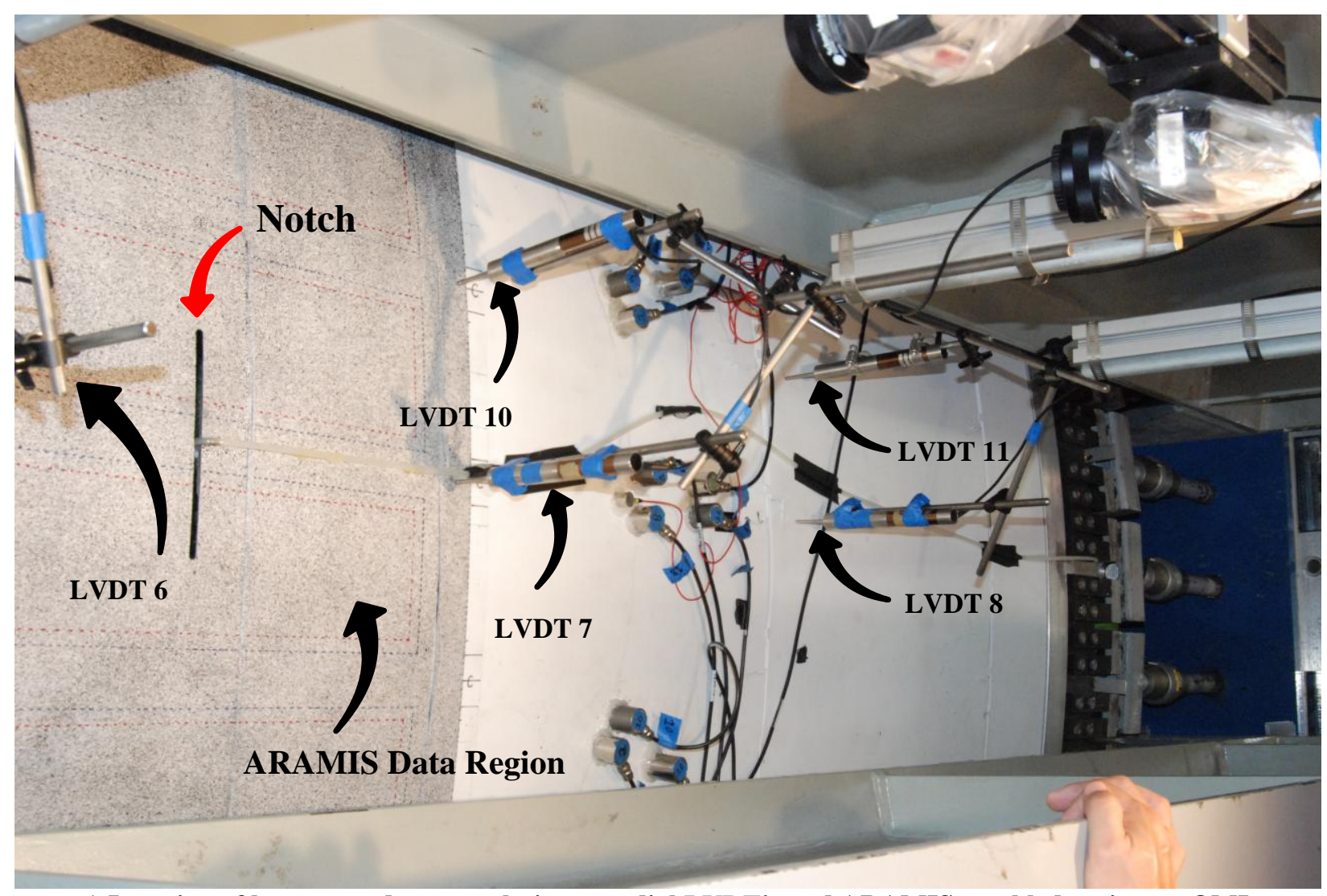

c) Location of large area damage relative to radial LVDT's and ARAMIS speckled region on OML

Figure 6. Large area damage. 


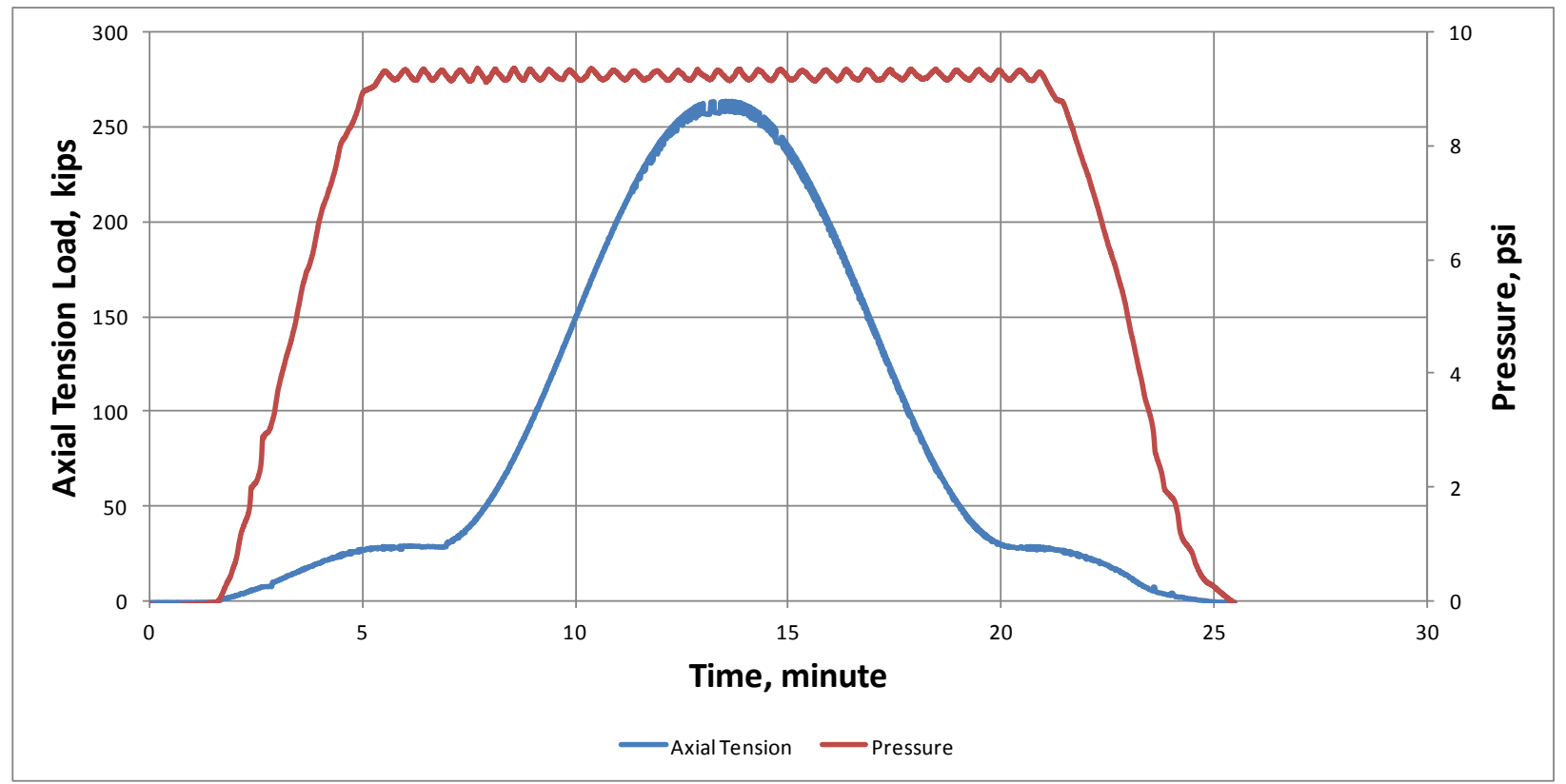

Figure 7. Typical loading, phase I combined $100 \%$ DLL pressure and axial tension load. 


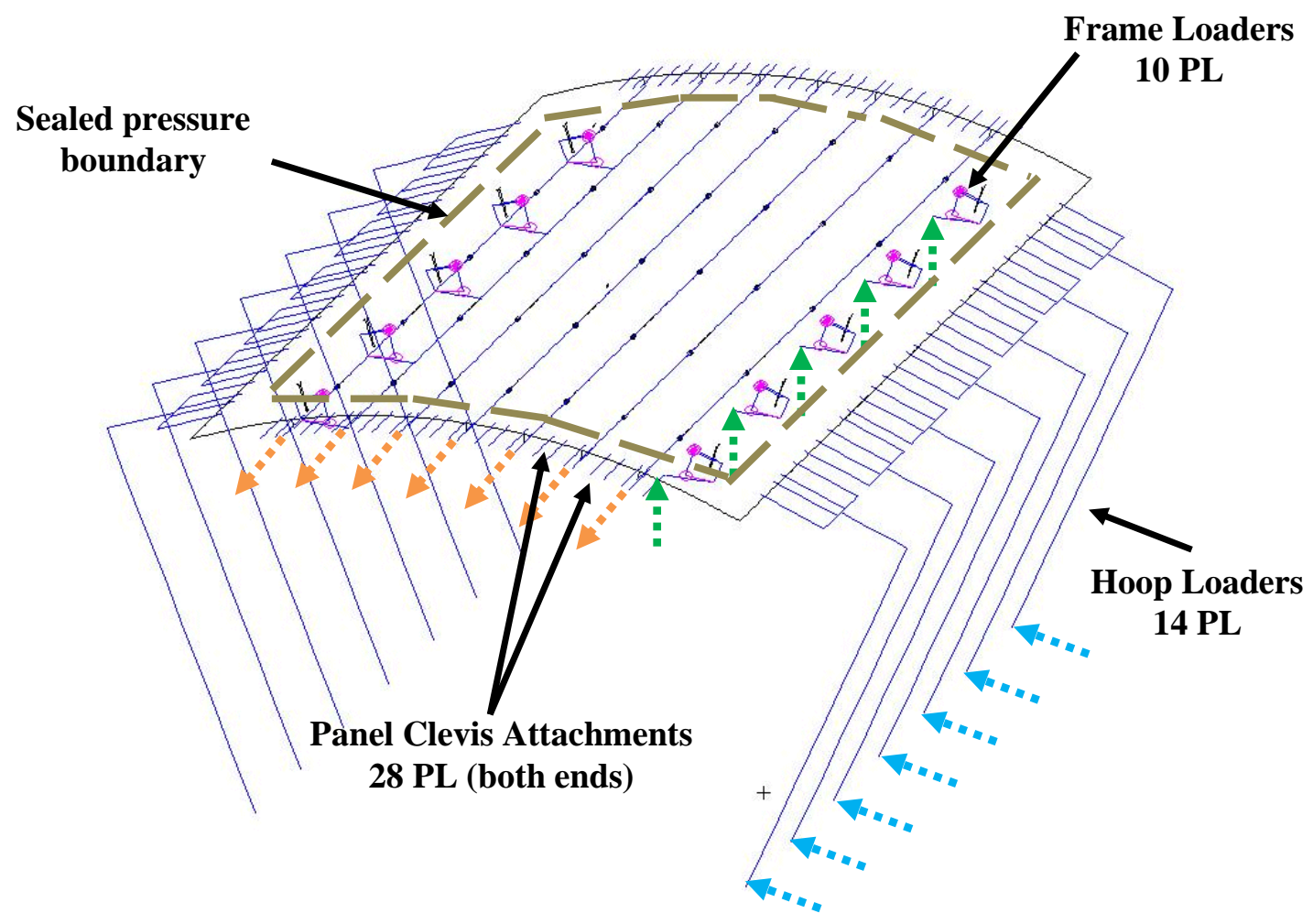

a) Phase I (pristine) FEM

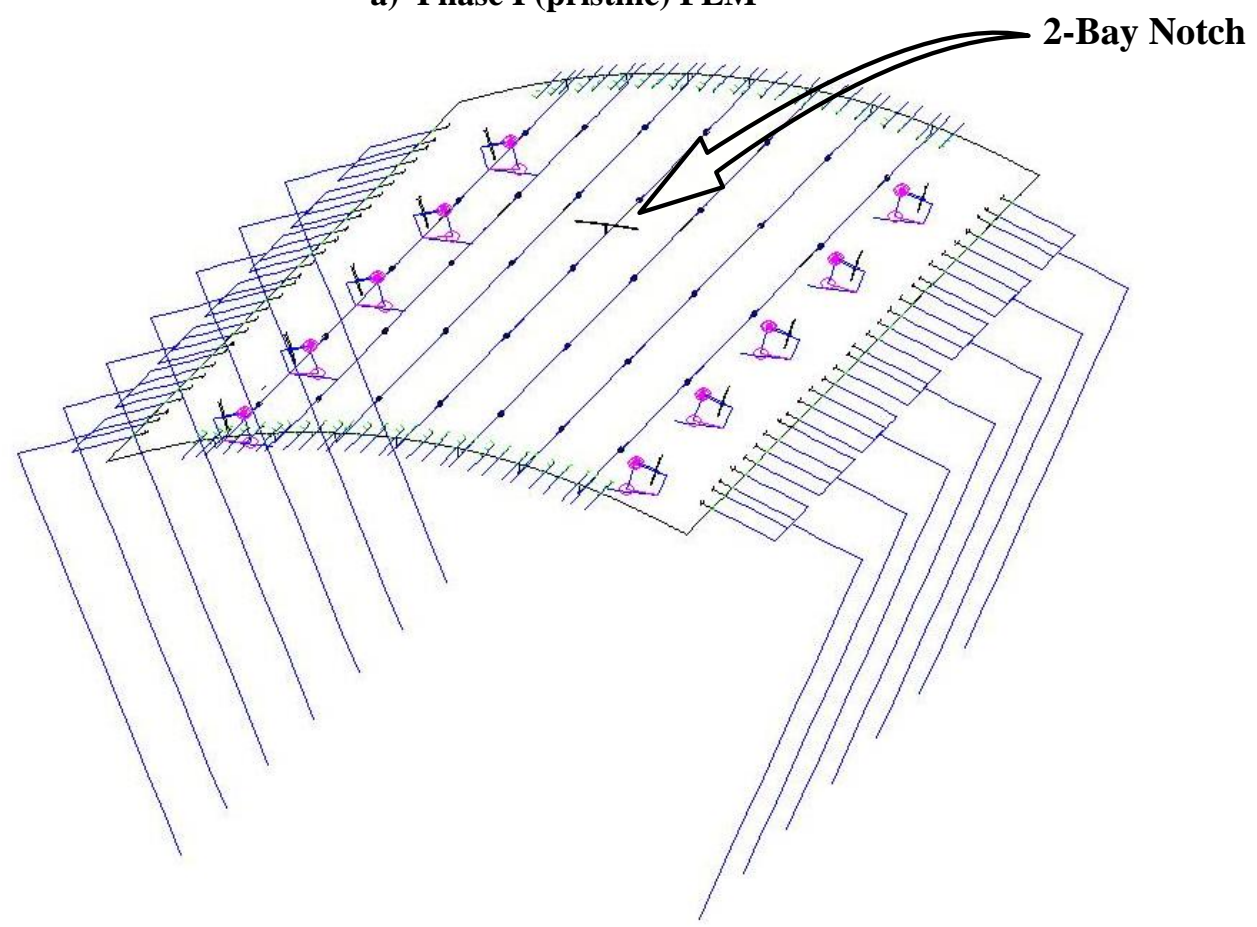

b) Phase III (2-bay discrete damage) FEM

Figure 8. Finite element models (wireframe illustration). 


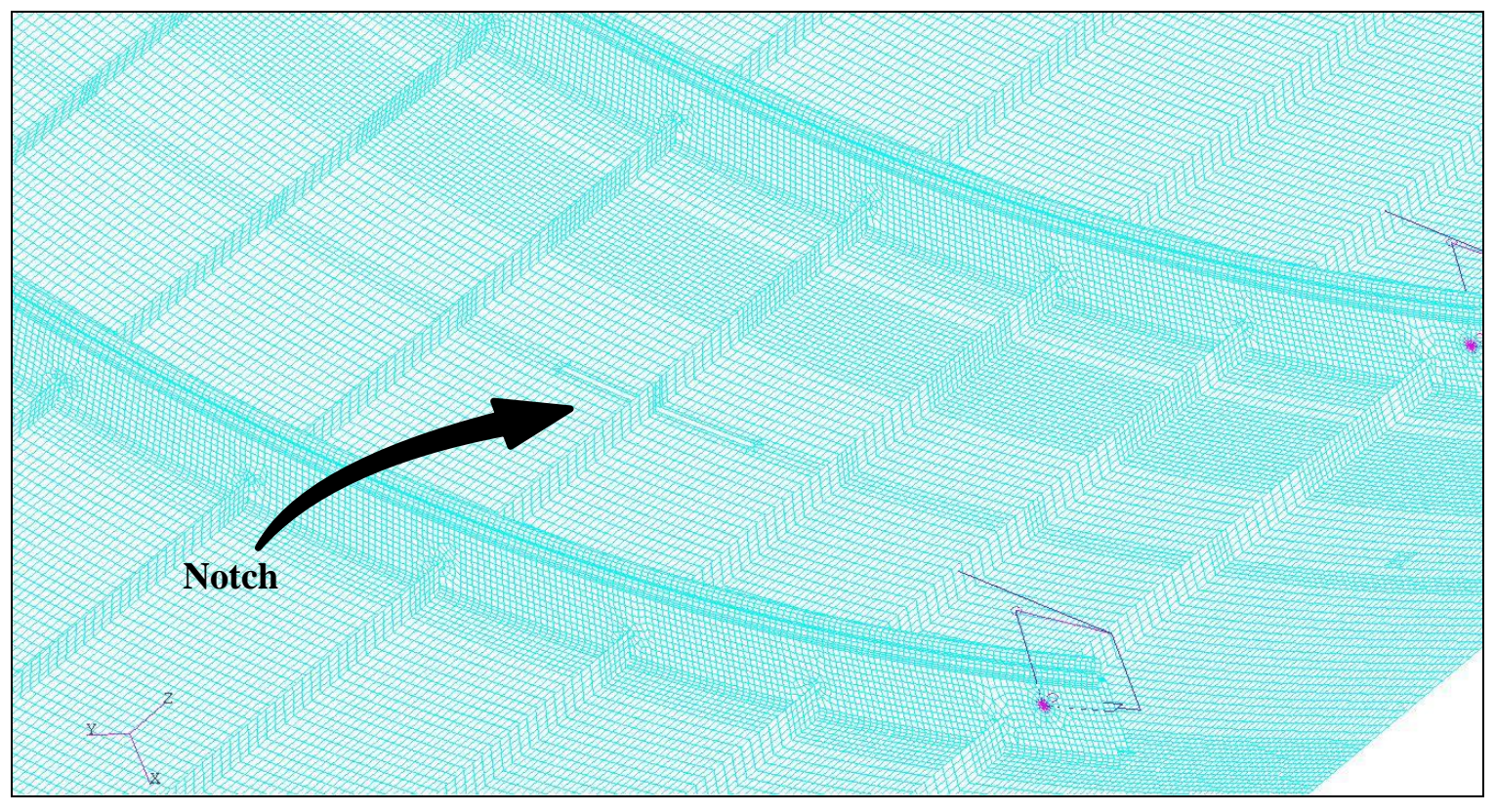

a) Mesh of panel in test section

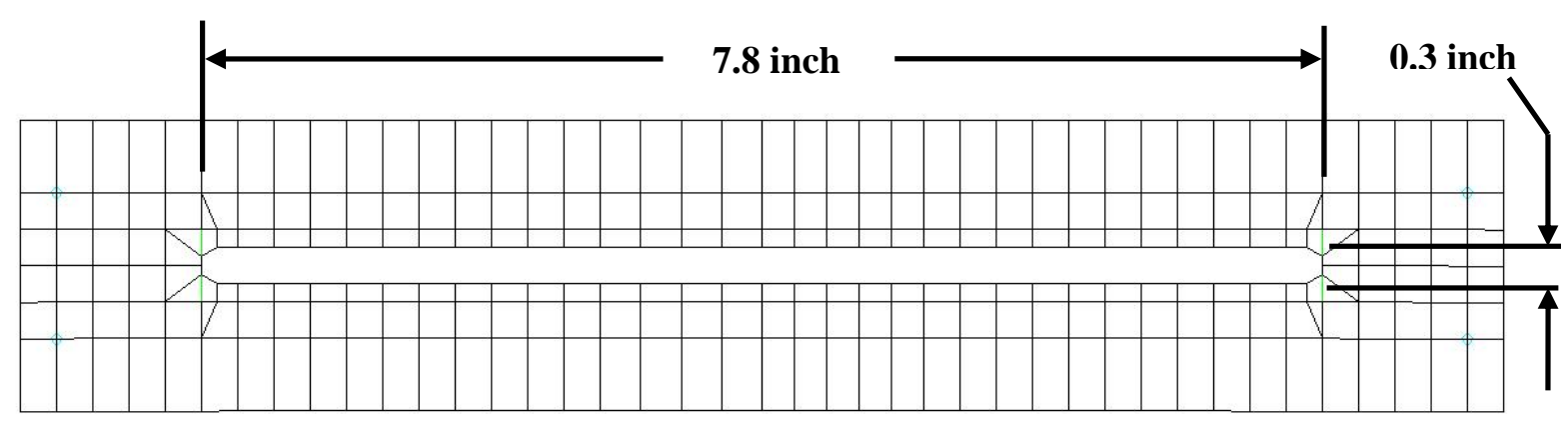

b) Mesh density around notch

Figure 9. Curved PRSEUS test panel mesh density details. 


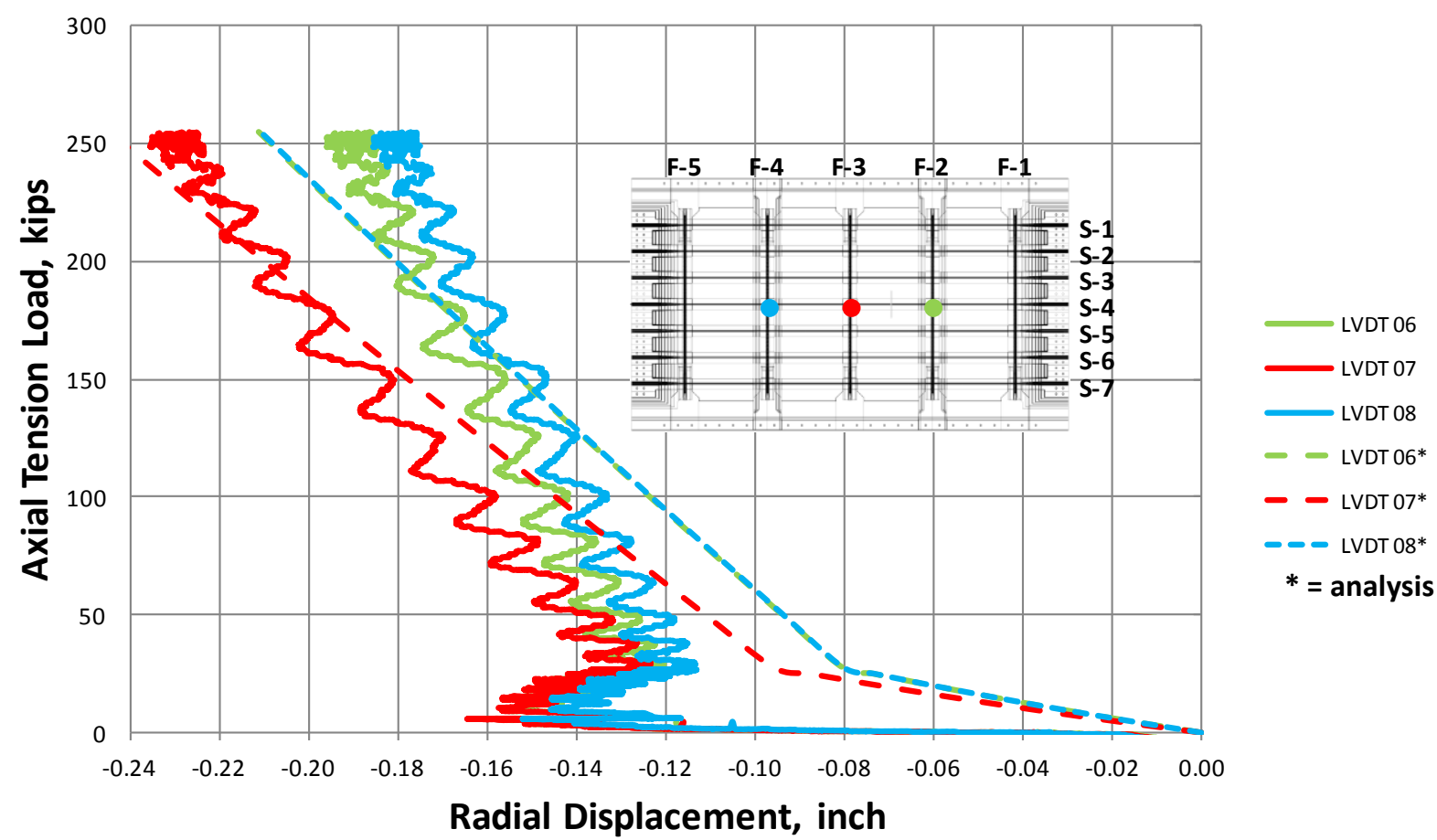

a) Radial

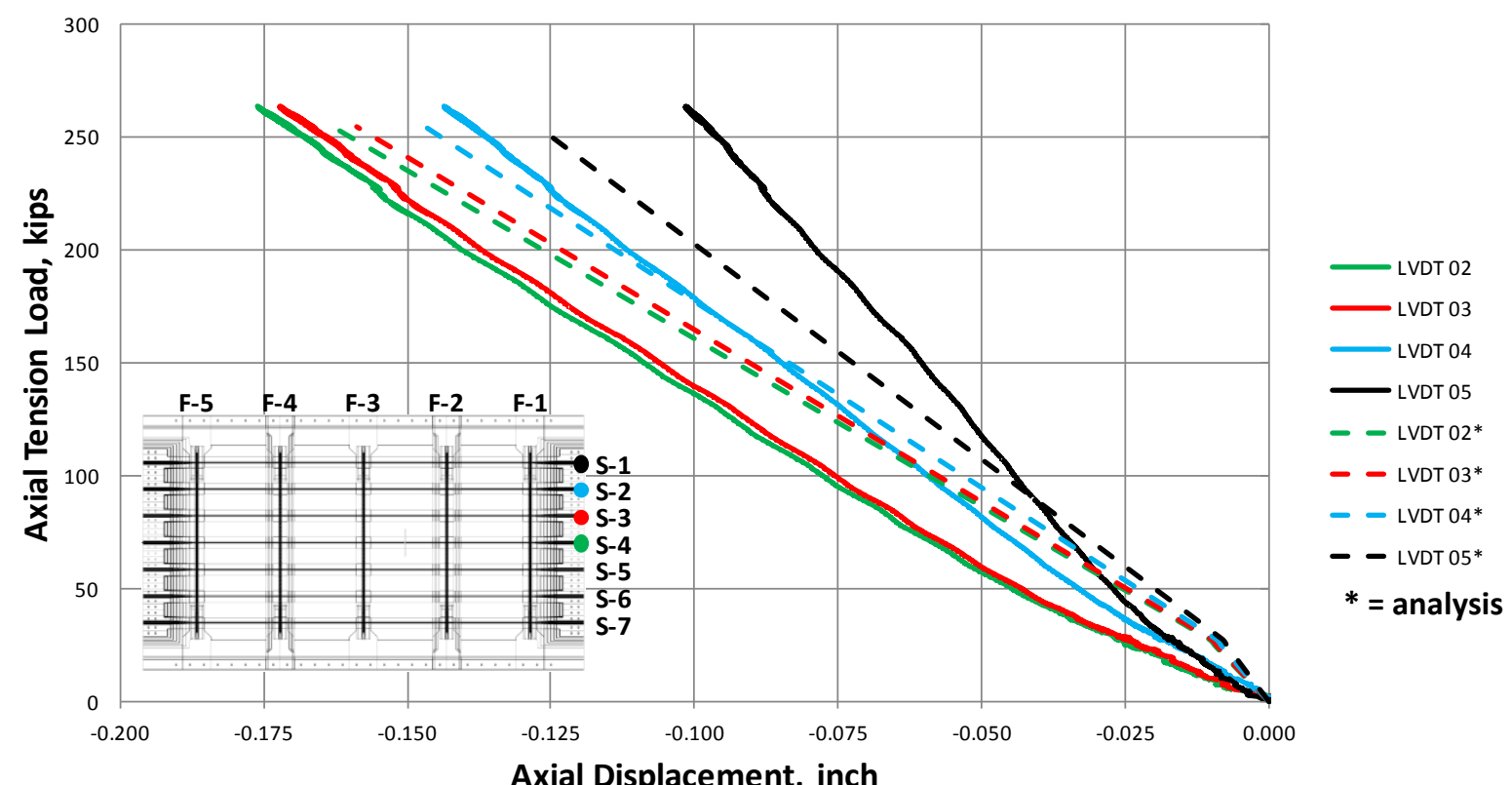

b) Axial

Figure 10. Phase I displacements, combined $100 \%$ P pressure and $100 \%$ DLL axial load. Negative displacement indicates an expansion or extension of the panel. 


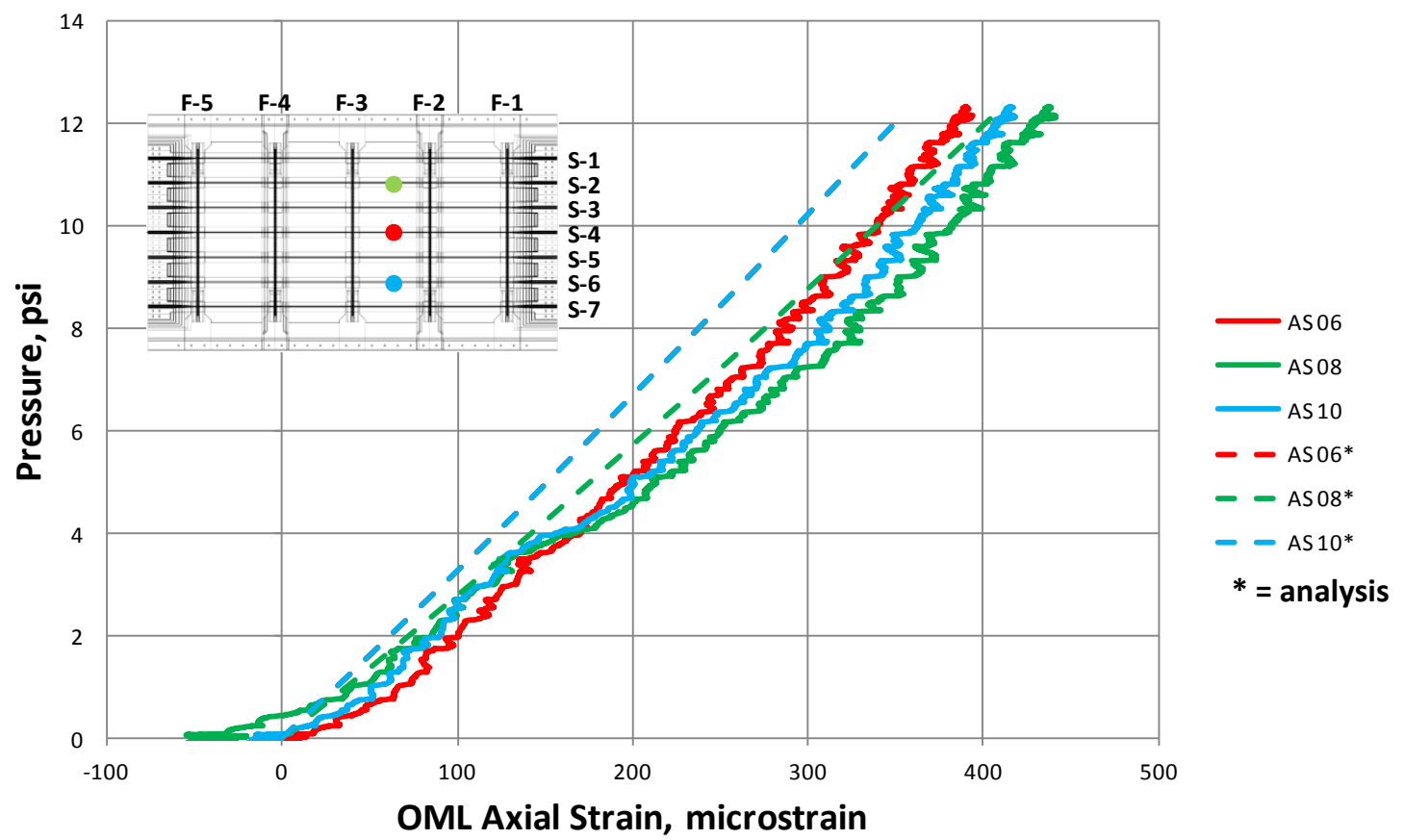

a) Axial strain on skin over stringers between frames F-2 and F-3

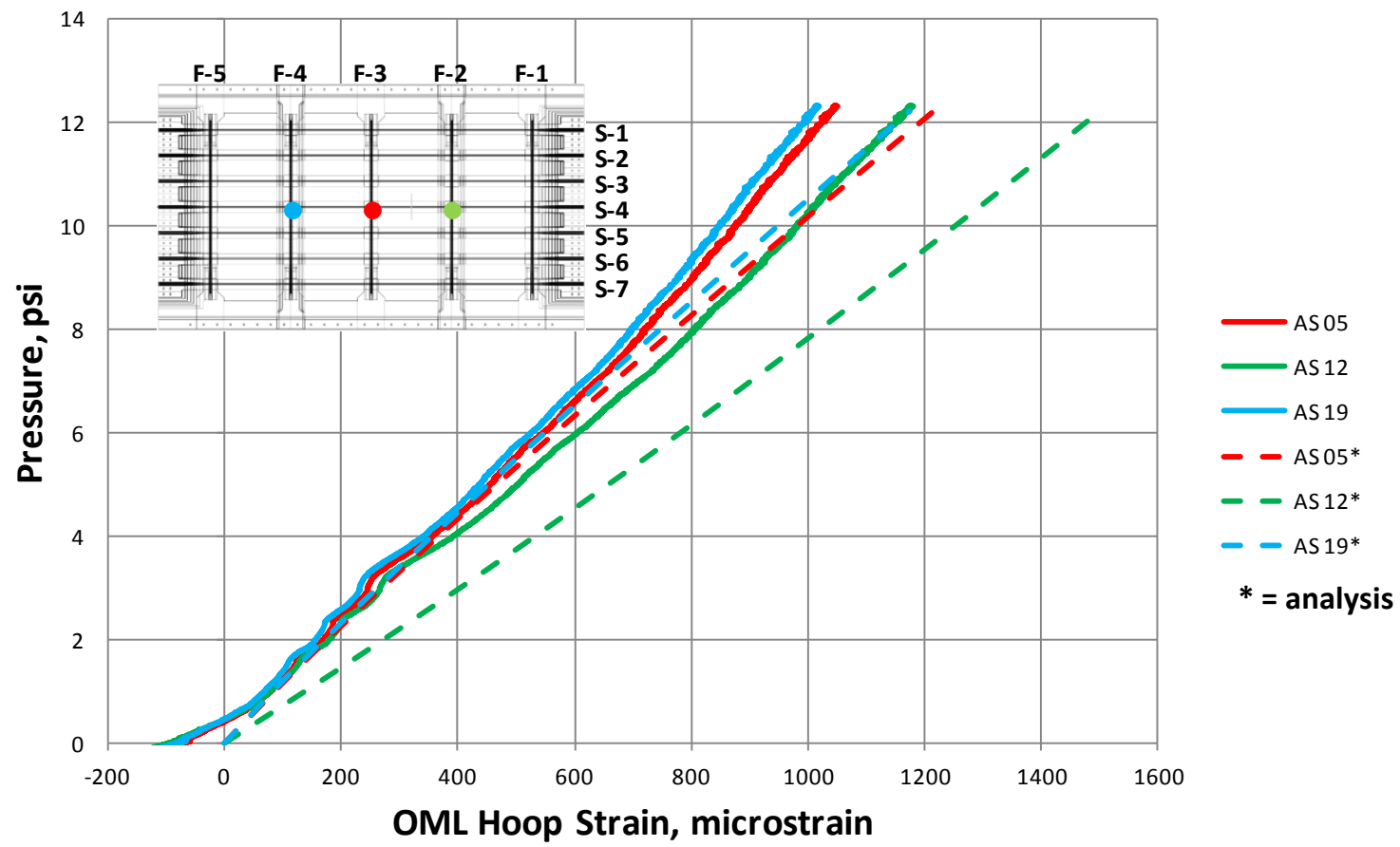

b) Hoop strain at frames F-2, F-3 and F-4 at panel centerline

Figure 11. Phase I strains, $100 \%$ P pressure only load. 


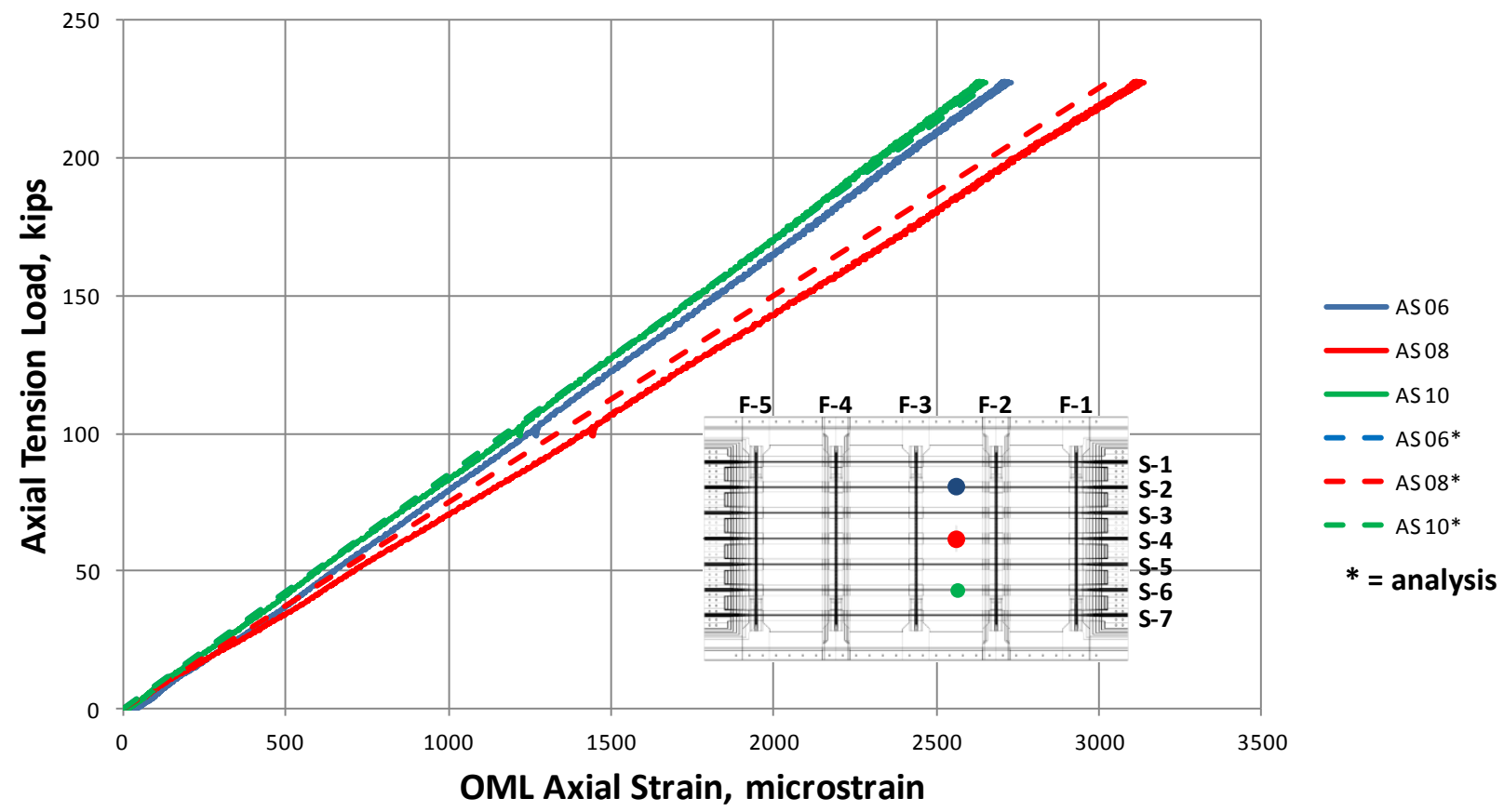

a) Axial strain on skin over stringers between frames F-2 and F-3

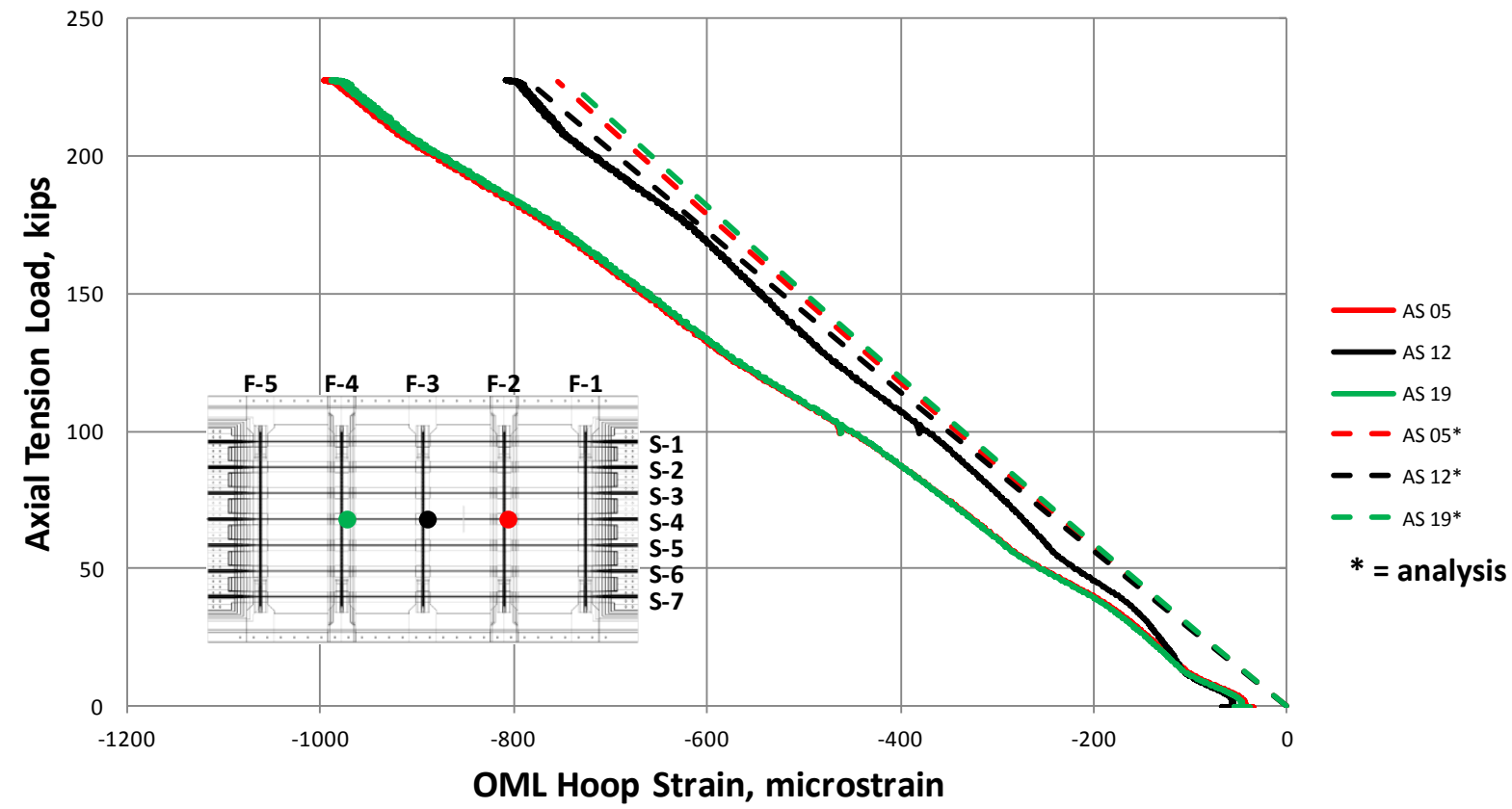

b) Hoop strain at frames F-2, F-3 and F-4 at panel centerline

Figure 12. Phase I strains, $100 \%$ DLL axial only load. 


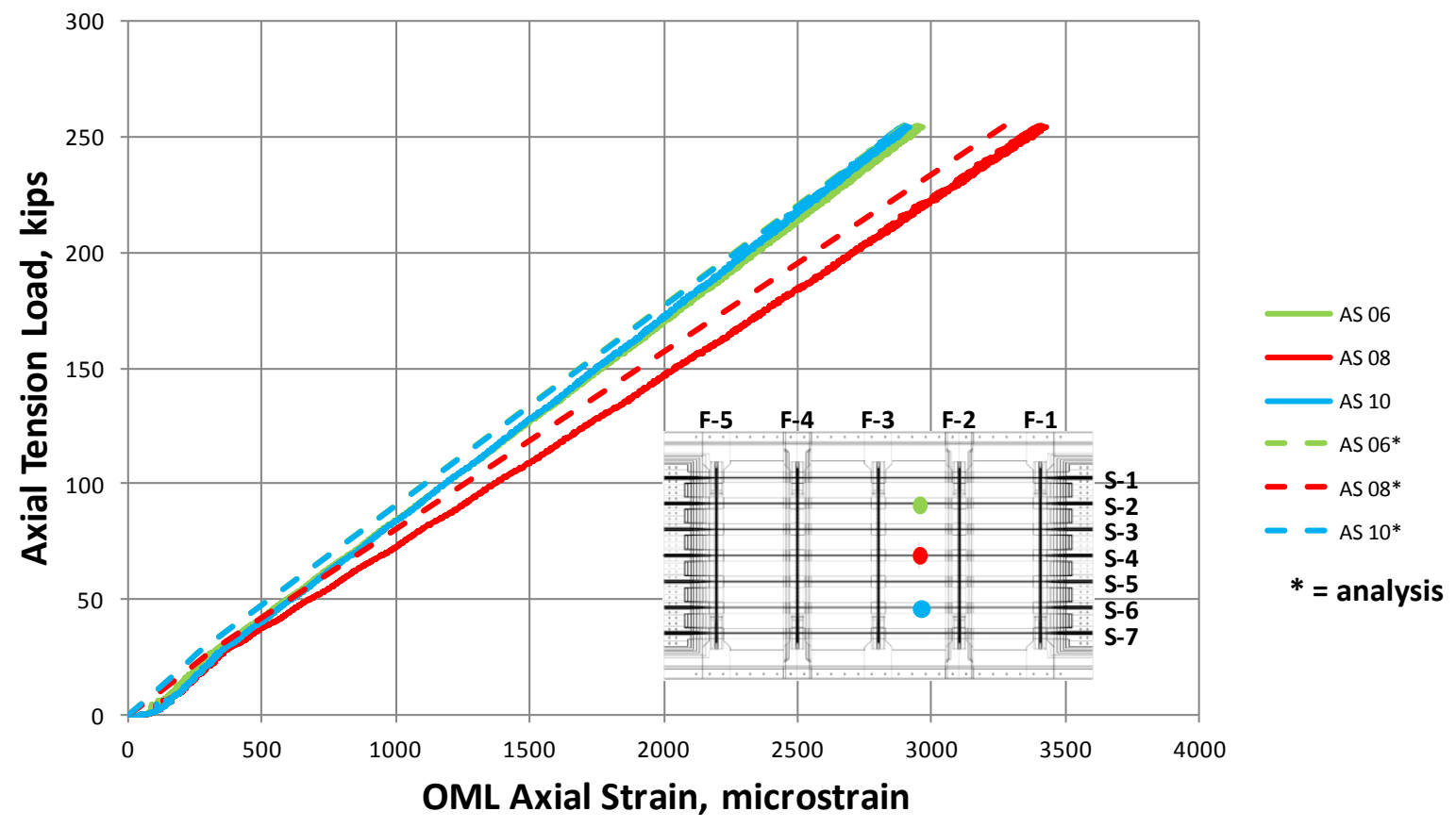

a) Axial strain on skin over stringers between frames F-2 and F-3

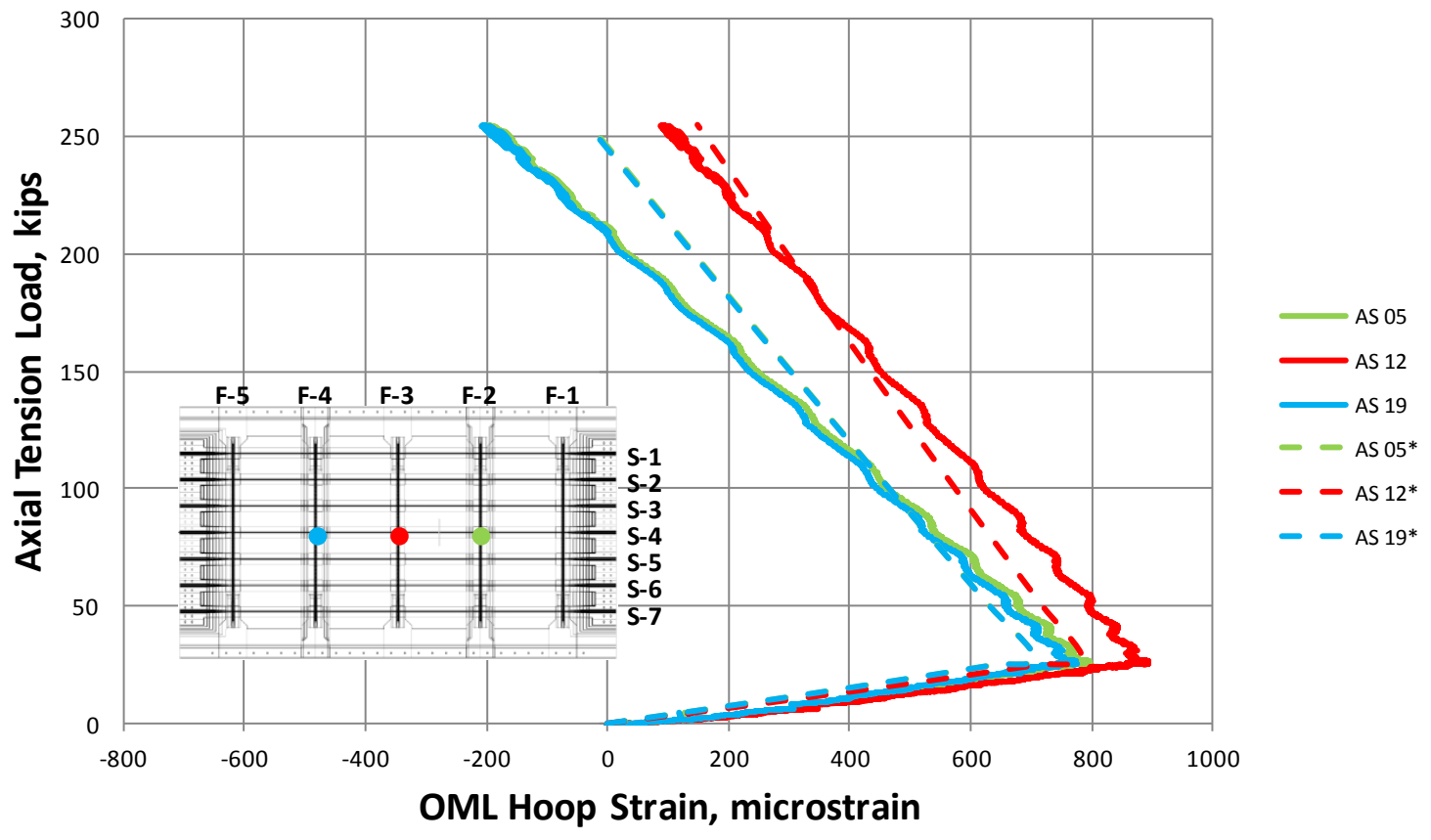

b) Hoop strain at frames F-2, F-3 and F-4 at panel centerline

Figure 13. Phase I strains, combined $100 \%$ P pressure and $100 \%$ DLL axial load. 


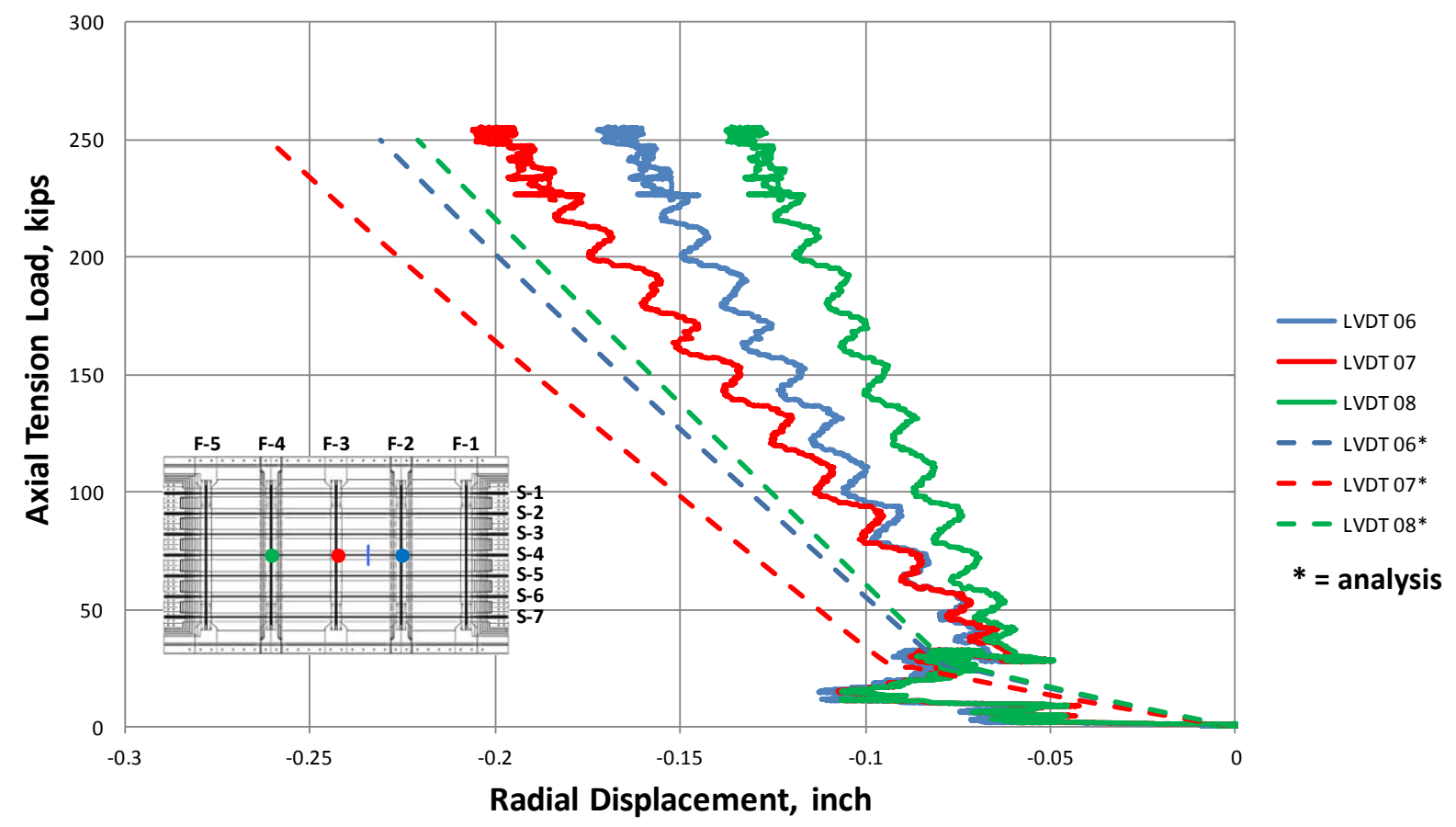

a) Radial

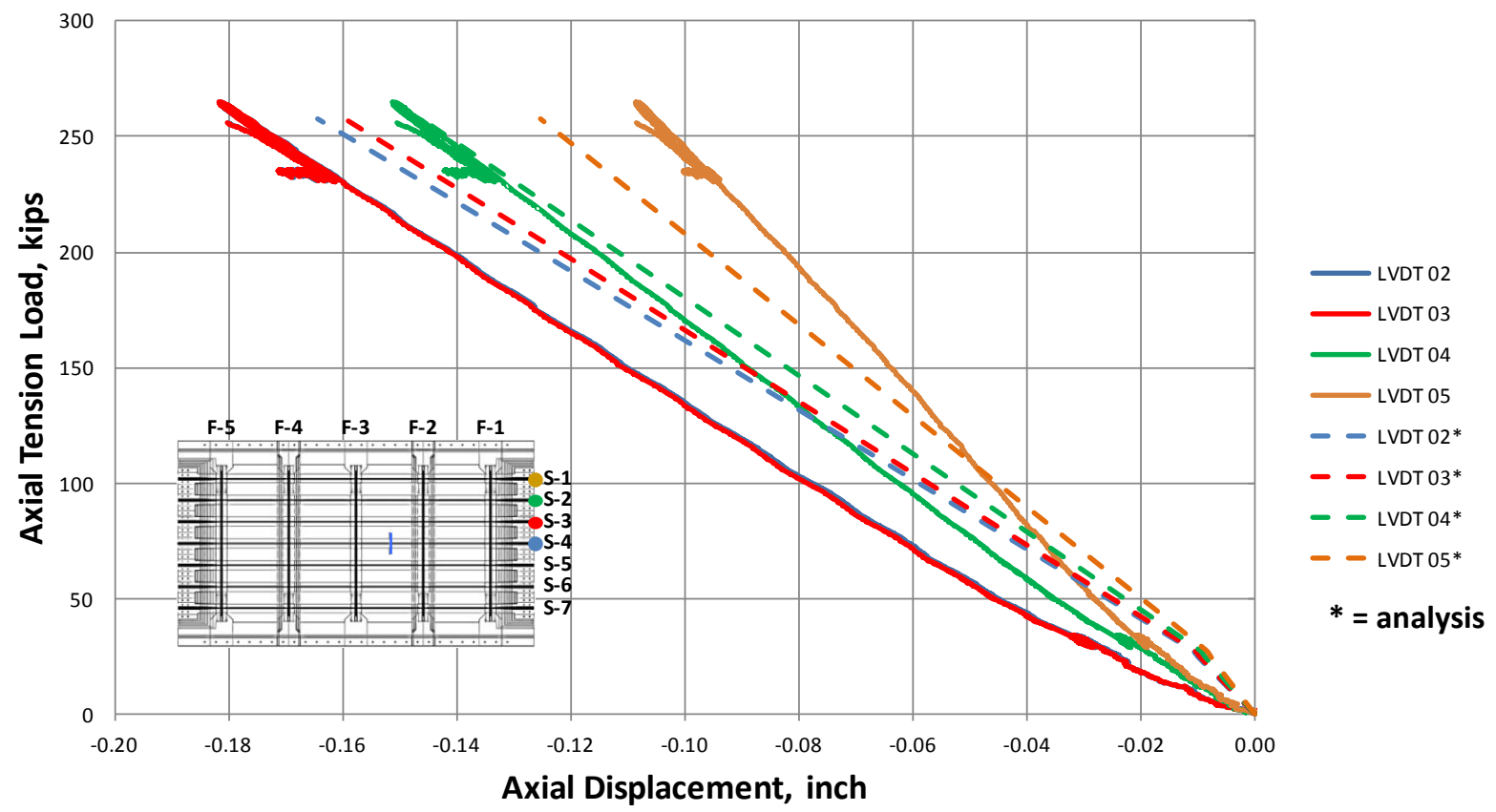

b) Axial

Figure 14. Phase III displacements, combined $100 \%$ P pressure and $100 \%$ DLL axial load. 


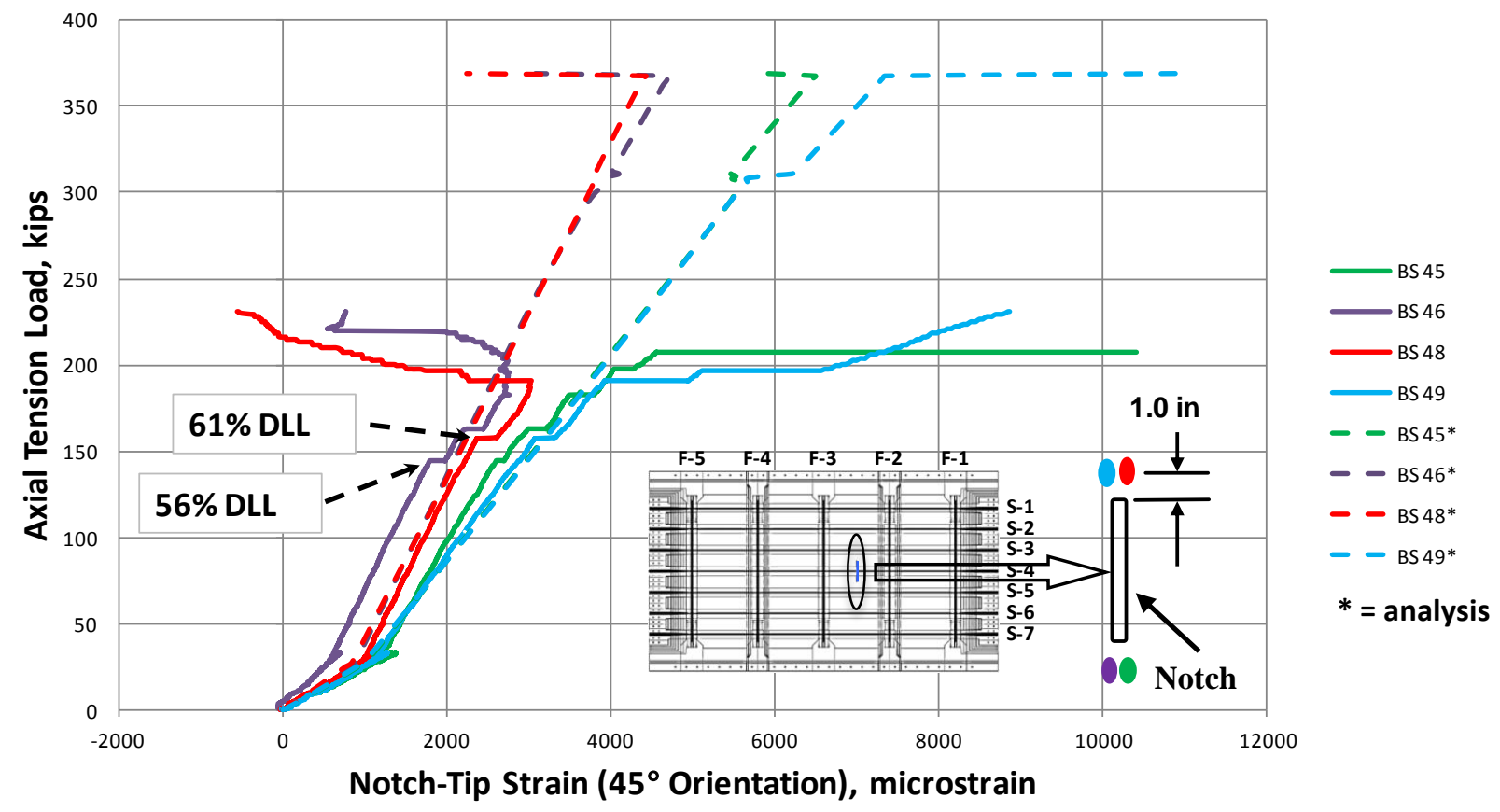

a) Skin between stringers adjacent to notch-tips on IML

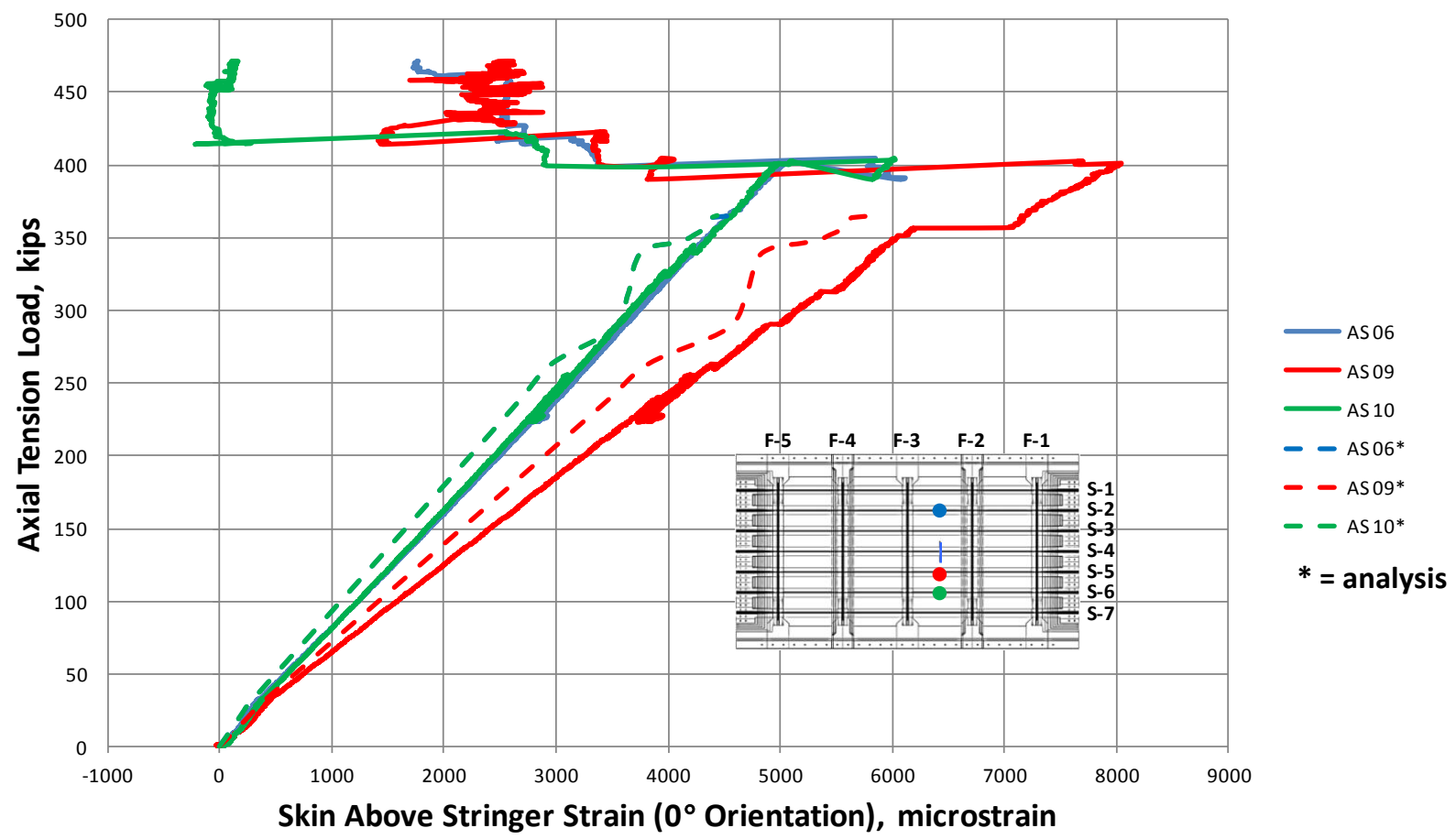

b) Skin above stringers S-2, S-5 and S-6 along axis of notch on OML

Figure 15. Phase III axial strain in skin in notch region, combined $100 \% \mathrm{P}$ pressure and axial load to failure. 


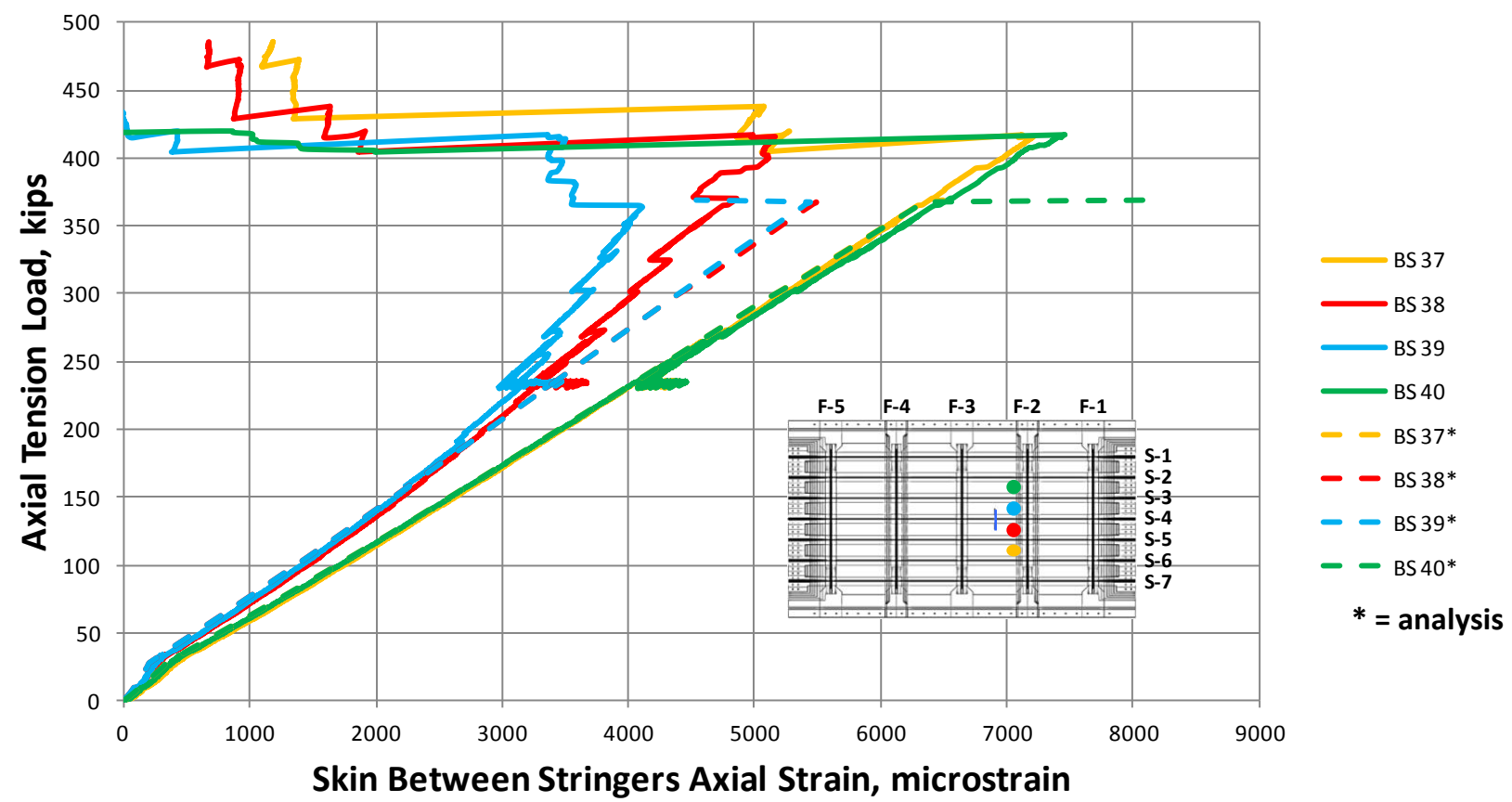

Figure 16. Phase III axial strian in the notch region, combined $100 \% \mathrm{P}$ pressure and axial load to failure. 

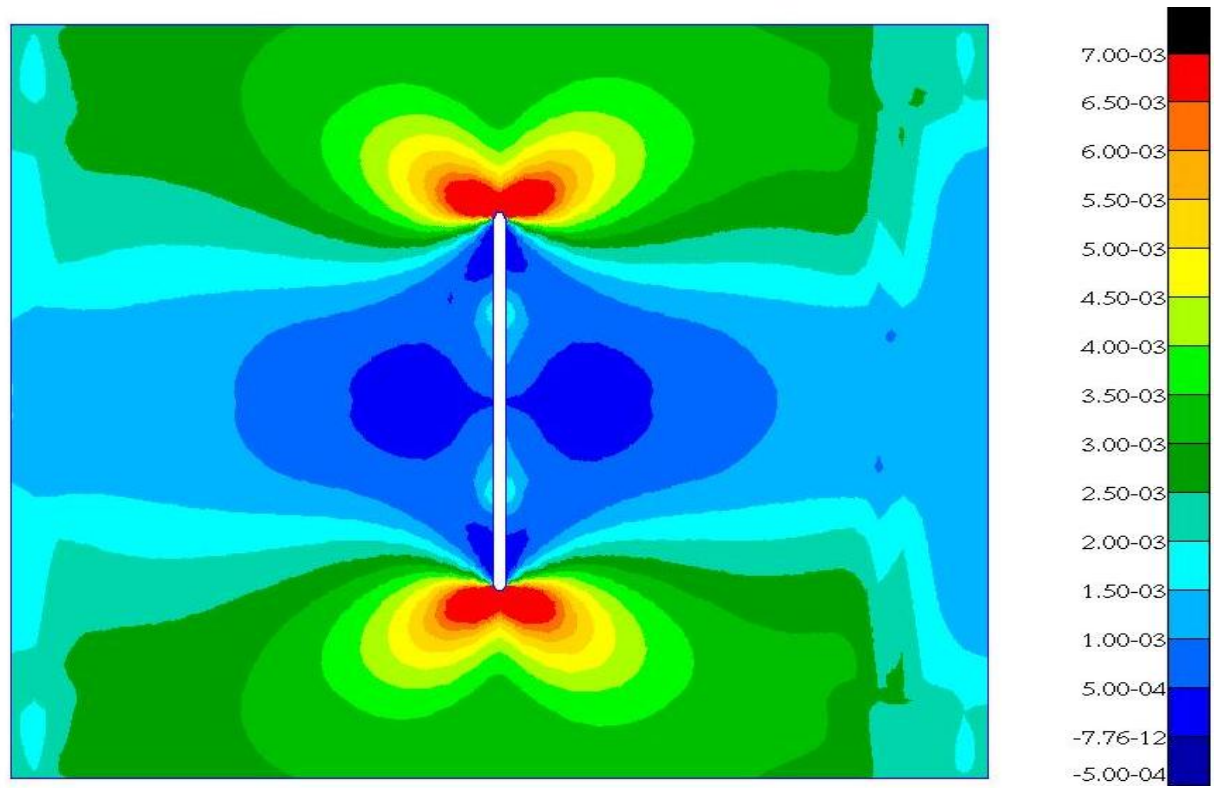

a) Calculated $100 \%$ P + 70\% Axial DLL
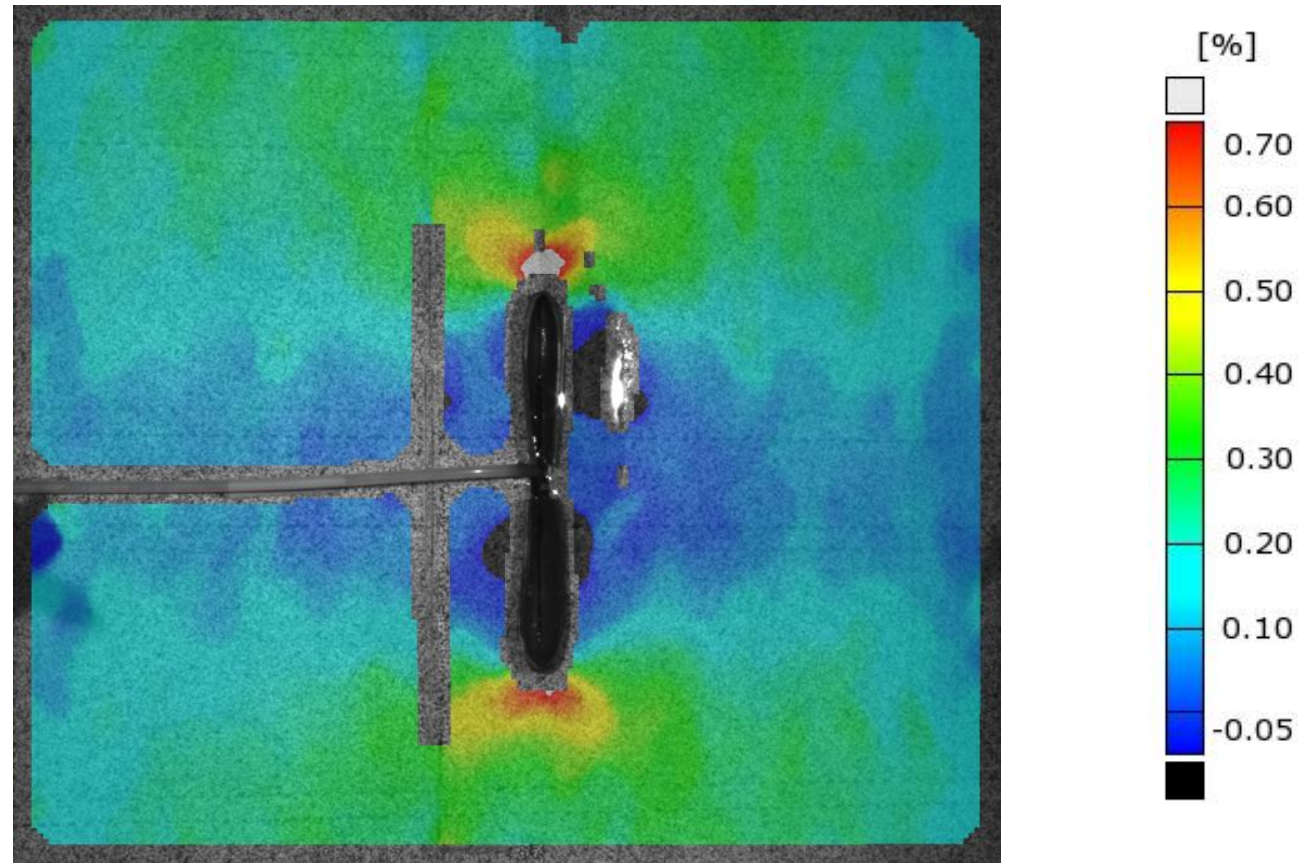

b) Recorded, $100 \%$ P + 68\% Axial DLL

Figure 17 Phase III speckled-region axial strain from analysis and test. 

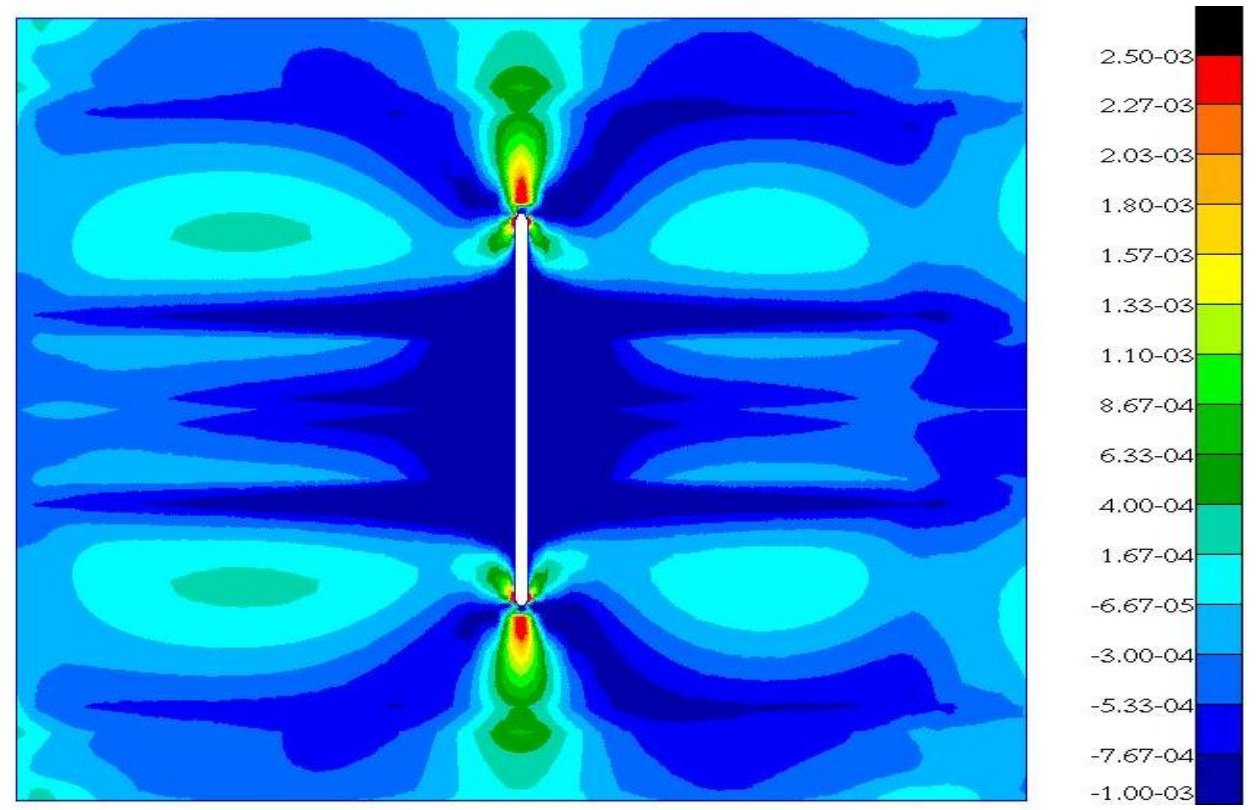

a) Calculated, $100 \%$ P + 70\% Axial DLL
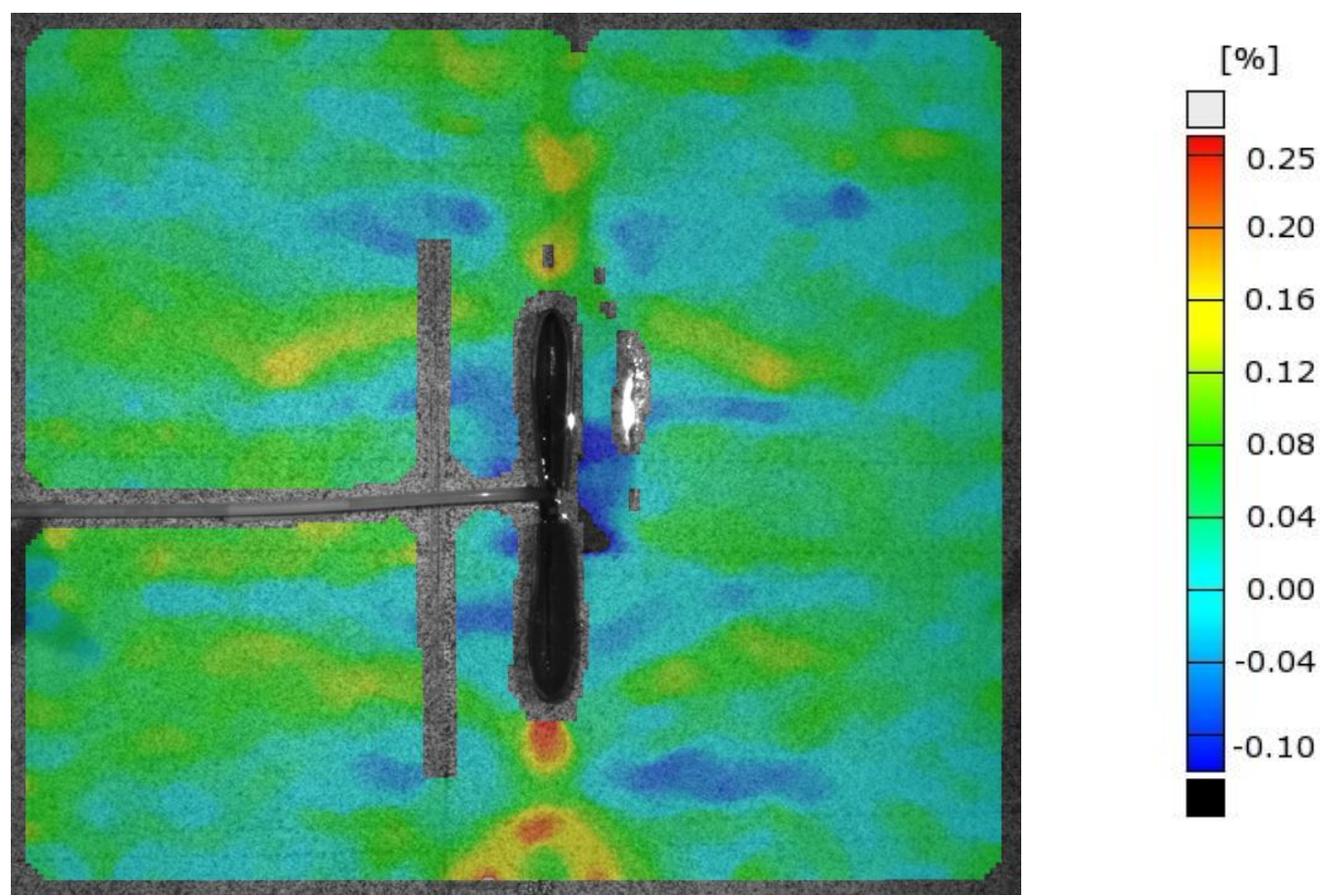

b) Recorded, $100 \%$ P + 68\% Axial DLL

Figure 18. Phase III speckled-region hoop strain from analysis and test. 

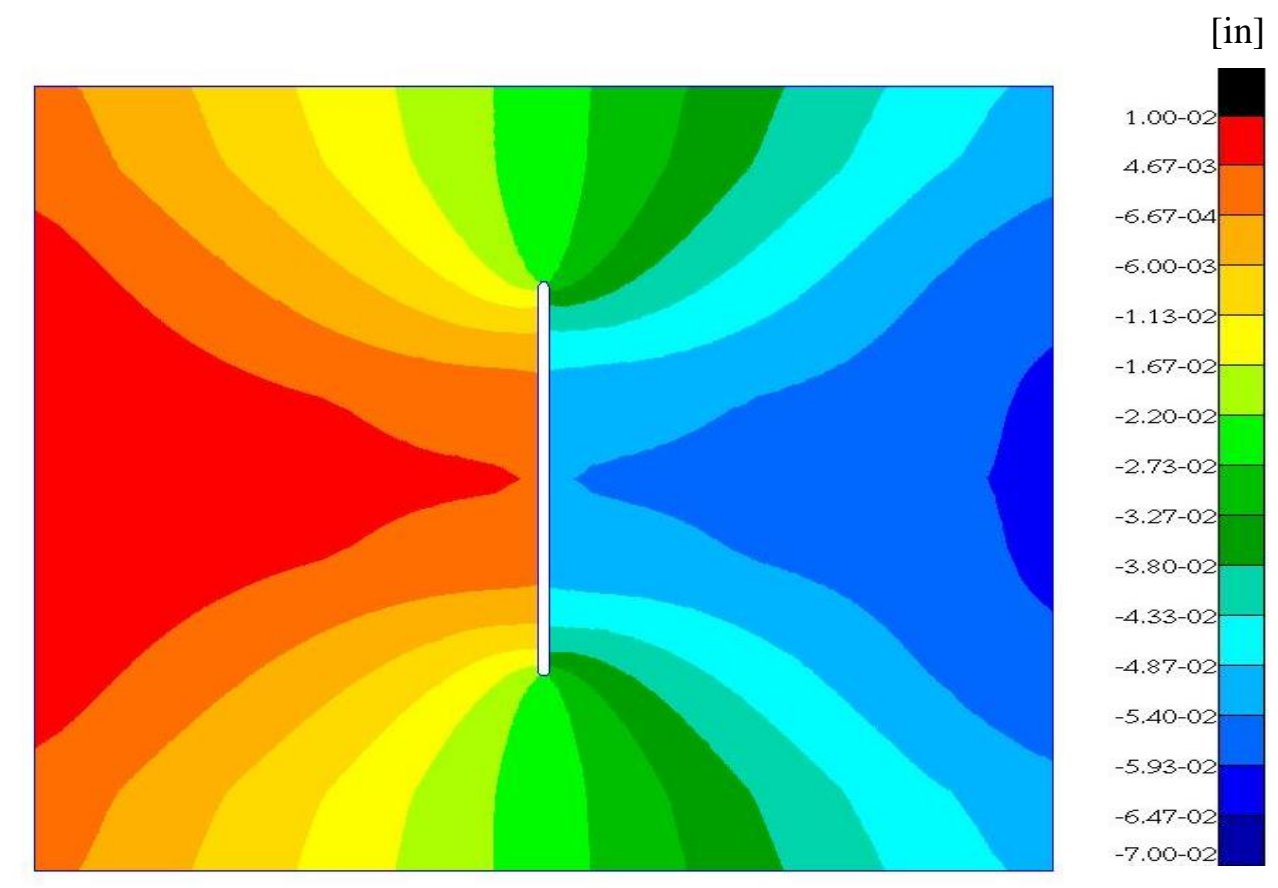

a) Calculated, $100 \%$ P + 70\% Axial DLL
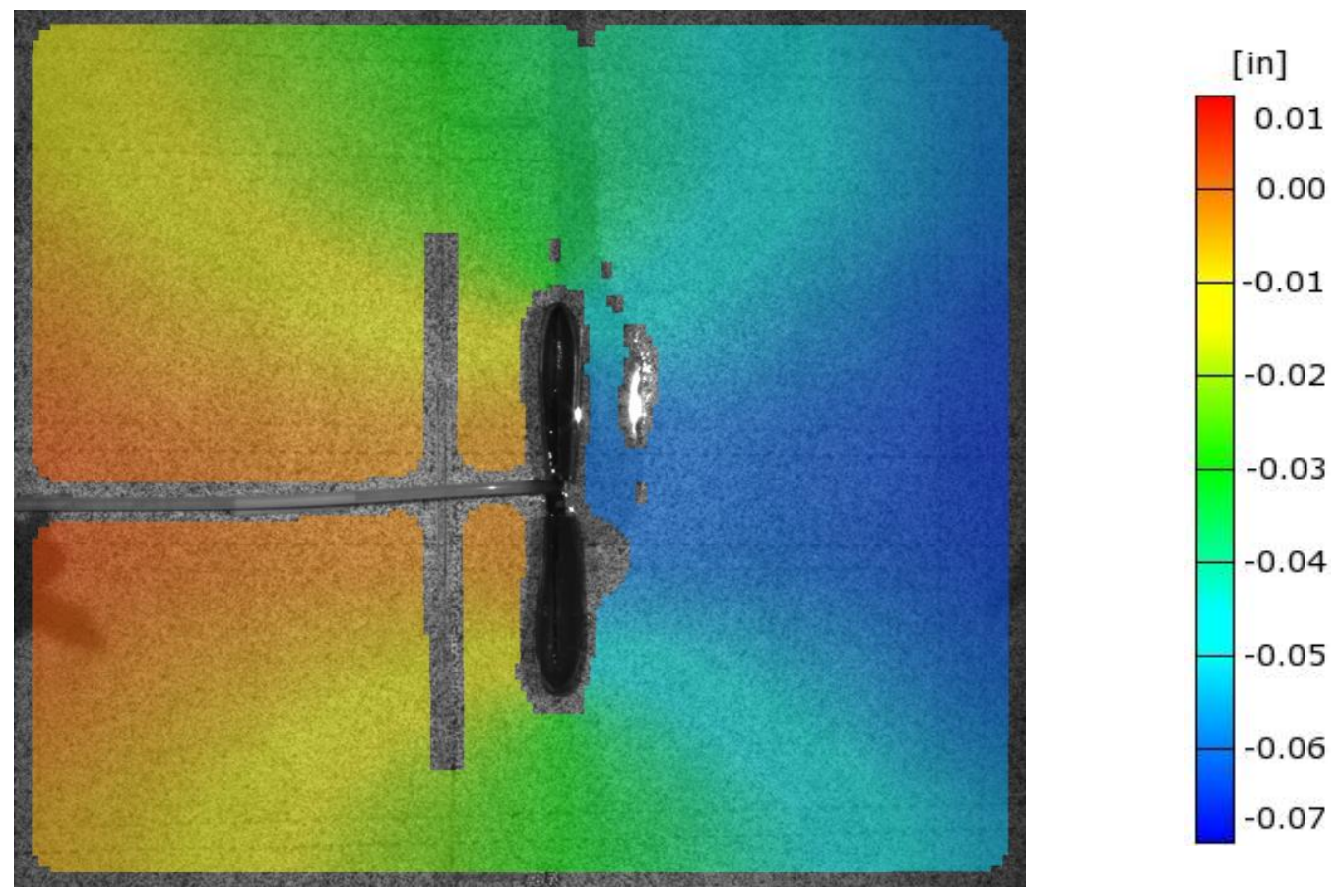

b) Recorded, $100 \%$ P + $68 \%$ Axial DLL

Figure 19. Phase III speckled-region axial displacement analysis and test. Scale is in inches. 


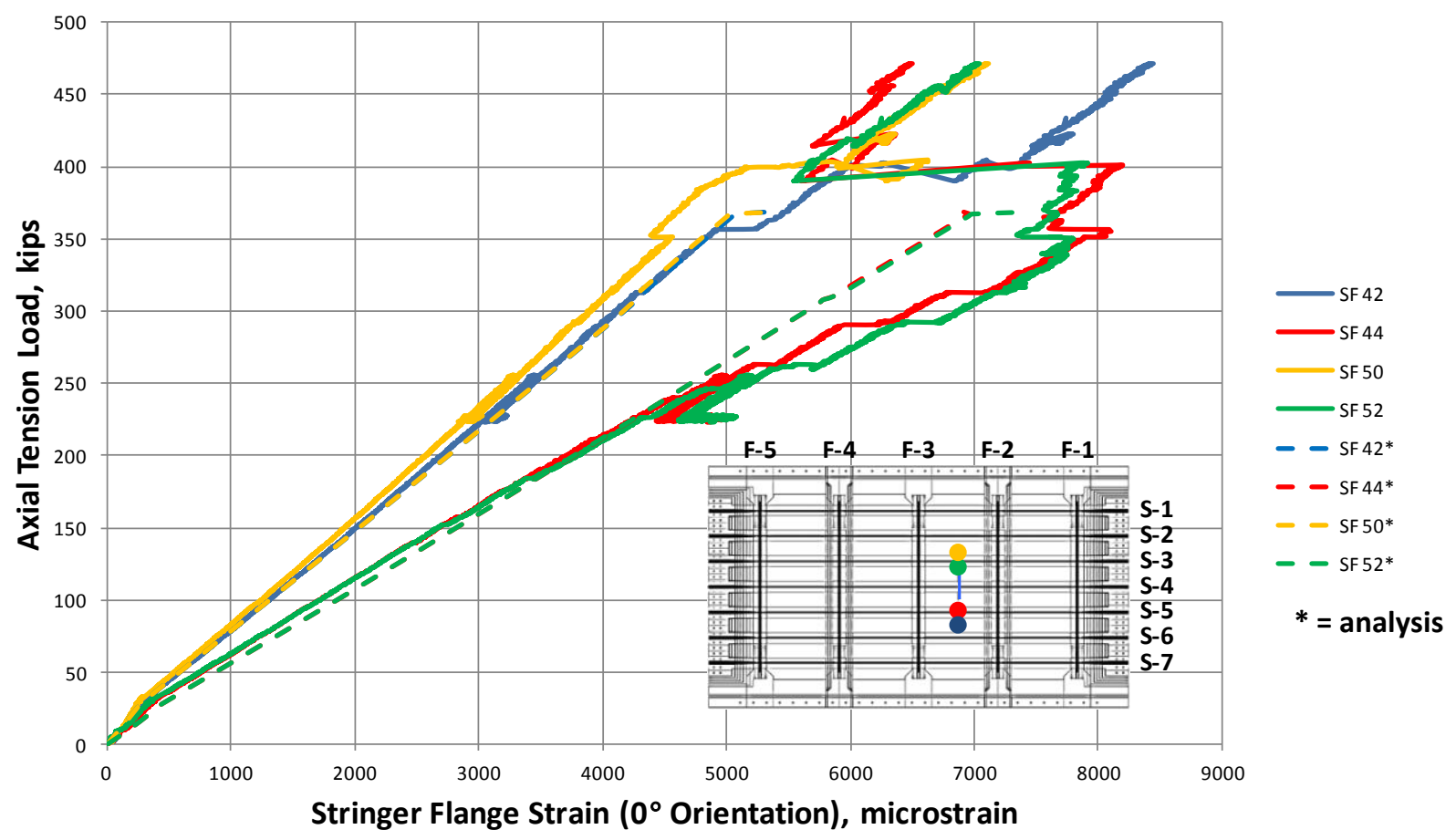

a) Stringer flanges

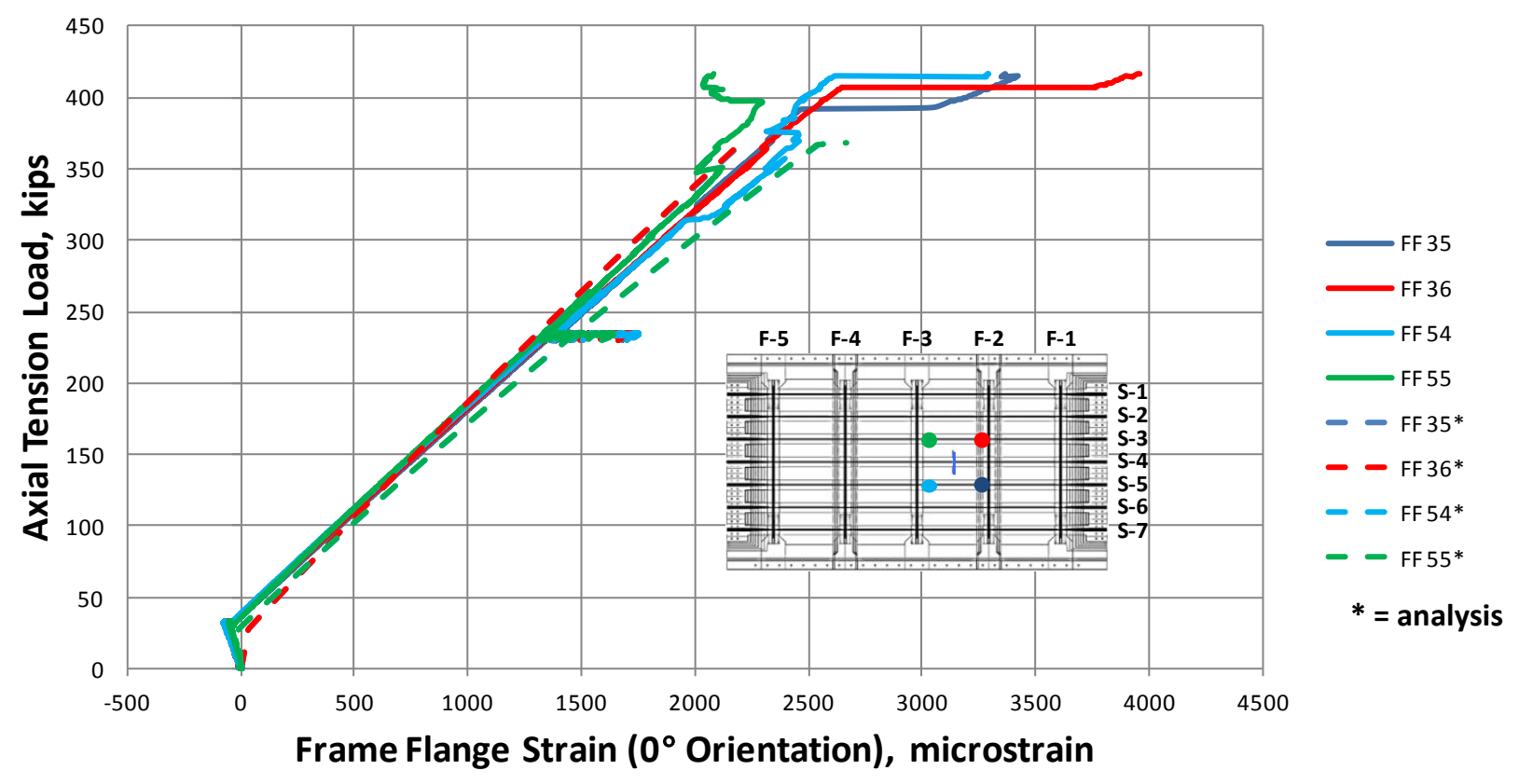

b) Frame flanges

Figure 20. Phase III strains in flanges adjacent to notch tip on IML, combined $100 \% \mathrm{P}$ pressure and axial to failure. 

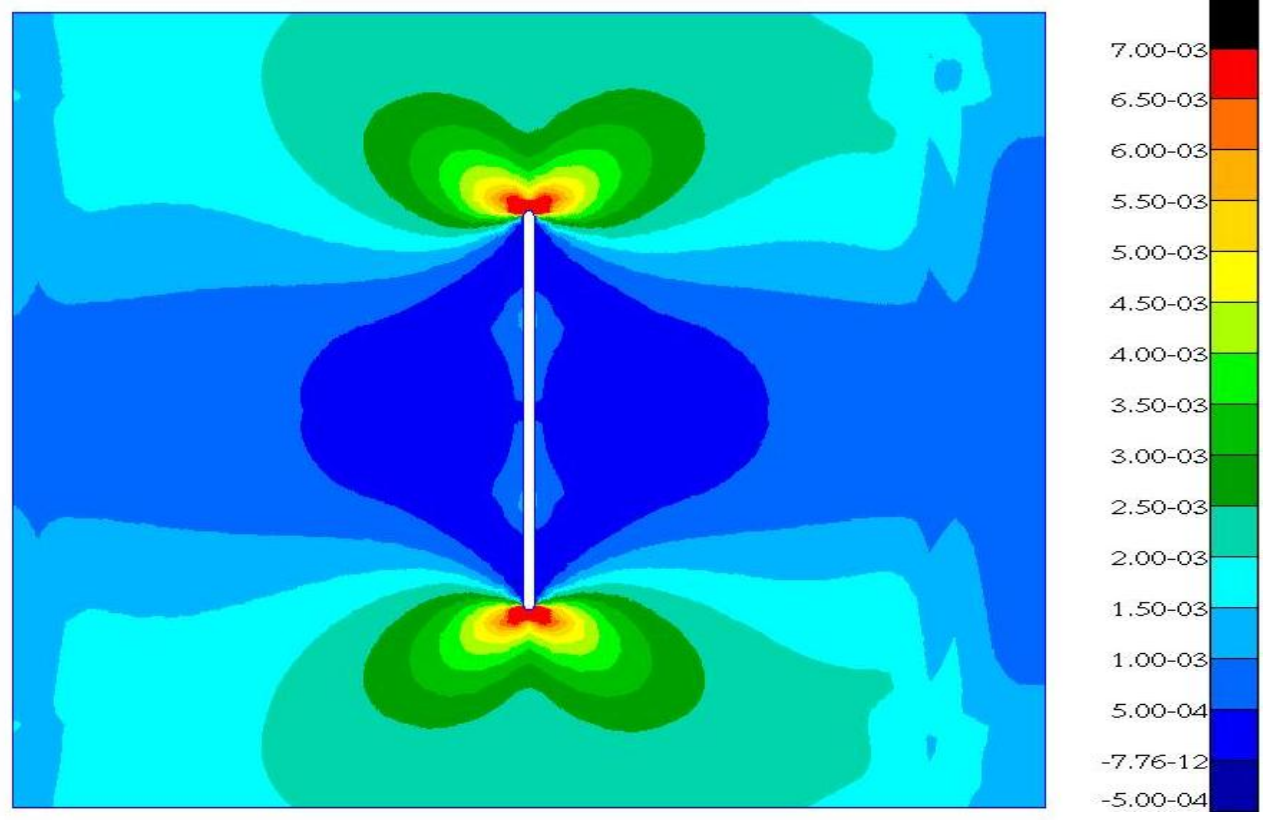

a) Calculated, $100 \% \mathrm{P}+\mathbf{5 0 \%}$ Axial DLL.
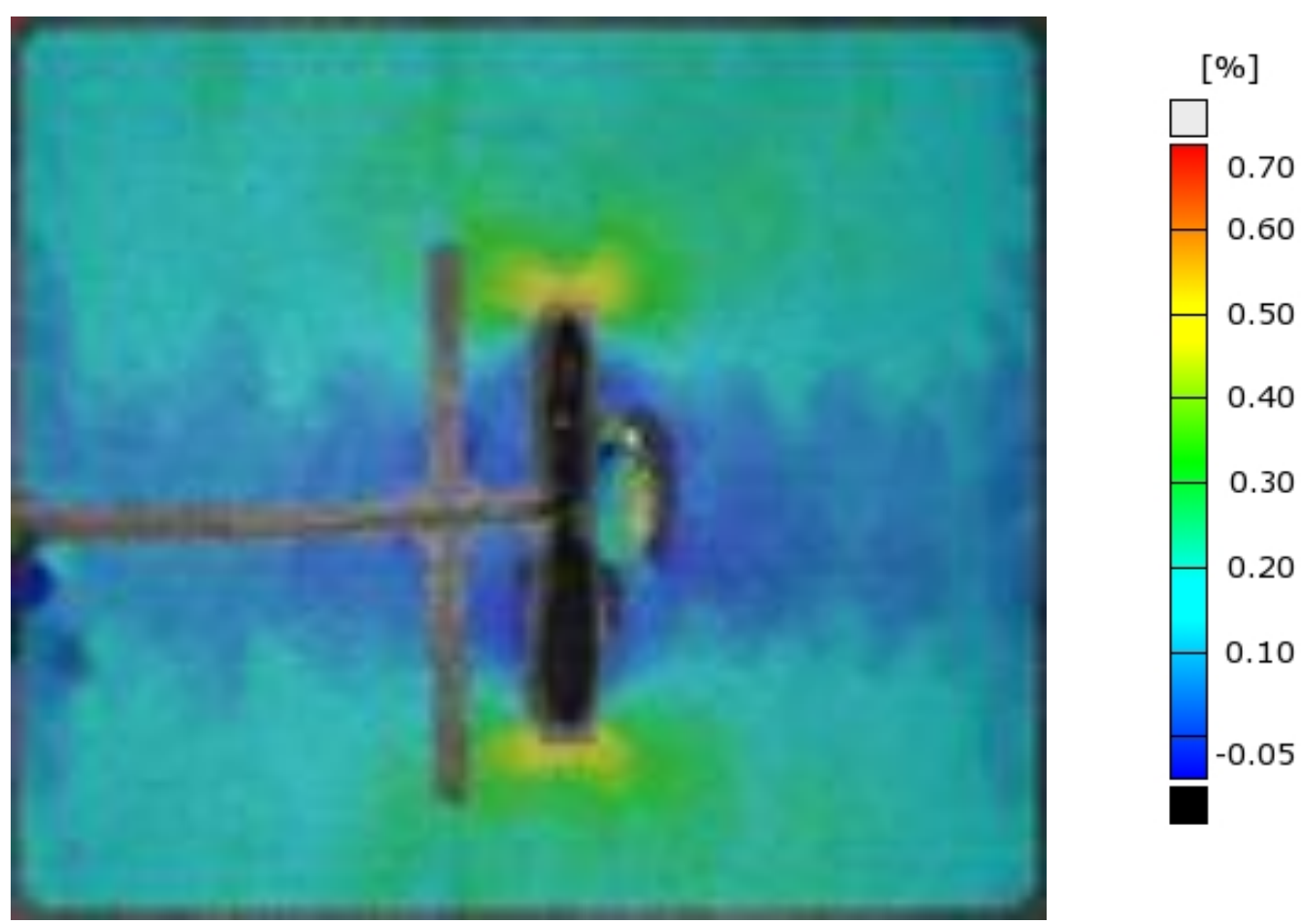

b) Recorded, $100 \%$ P + 55\% Axial DLL.

Figure 21. Phase III speckled-region axial strain from analysis and test. 